\title{
Investigating the Variability of High-Elevation Seasonal Orographic Snowfall Enhancement and Its Drivers across Sierra Nevada, California
}

\author{
LAURIE S. HUNING \\ Department of Civil and Environmental Engineering, University of California, Irvine, Irvine, and Department of \\ Civil and Environmental Engineering, University of California, Los Angeles, Los Angeles, California \\ STEVEn A. MARGUlis \\ Department of Civil and Environmental Engineering, University of California, Los Angeles, Los Angeles, California
}

(Manuscript received 28 October 2016, in final form 7 October 2017)

\begin{abstract}
While orographically driven snowfall is known to be important in mountainous regions, a complete understanding of orographic enhancement from the basin to the mountain range scale is often inhibited by limited distributed data and spatial and/or temporal resolutions. A novel, 90-m spatially distributed snow water equivalent (SWE) reanalysis was used to overcome these limitations. Leveraging this SWE information, the interannual variability of orographic gradients in cumulative snowfall (CS) was investigated over 14 windward (western) basins in the Sierra Nevada in California from water years 1985 to 2015. Previous studies have not provided a detailed multidecadal climatology of orographic CS gradients or compared wet-year and dry-year orographic CS patterns, distributions, and gradients across an entire mountain range. The magnitude of seasonal CS gradients range from over $15 \mathrm{~cm}$ SWE per $100-\mathrm{m}$ elevation to under $1 \mathrm{~cm}$ per $100 \mathrm{~m}$ with a 31-yr average of $6.1 \mathrm{~cm}$ per $100 \mathrm{~m}$ below $\sim 2500 \mathrm{~m}$ in the western basins. The $31-\mathrm{yr}$ average CS gradients generally decrease in higher elevation zones across the western basins and become negative at the highest elevations. On average, integrated vapor transport and zonal winds at $700 \mathrm{hPa}$ are larger during wet years, leading to higher orographically driven CS gradients across the Sierra Nevada than in dry years. Below $\sim 2500 \mathrm{~m}$, wet years yield greater enhancement (relative to dry years) by factors of approximately 2 and 3 in the northwestern and southwestern basins, respectively. Overall, the western Sierra Nevada experiences about twice as much orographic enhancement during wet years as in dry years below the elevation corresponding to the 31-yr average maximum CS.
\end{abstract}

\section{Introduction}

Wintertime orographic precipitation is an important process controlling the accumulation and distribution of the snowpack in high-elevation montane watersheds. Orographic precipitation results from the forced ascent of moist air over a mountain barrier. An accurate assessment of high-elevation gradients in total precipitation and snowfall across montane regions is still missing since limited in situ measurements generally inhibit a full spatiotemporal characterization of orographic precipitation from basin to mountain range scales (Lehning 2013; Kirchner et al. 2014). Without a more complete understanding of the elevational distribution of montane snowfall and snow water equivalent (SWE) accumulation,

Corresponding author: Laurie Huning, lhuning@uci.edu water resources are more challenging to quantify, predict, and manage.

Because of the high variability of the topography and surface characteristics in complex mountainous regions, there is often significant variability in the spatial patterns of snow accumulation resulting from localized orographic effects and atmospheric circulations (Dettinger et al. 2004; Lundquist et al. 2010). When compared to high-resolution distributed snow depth measurements, Kirchner et al. (2014) found that point-scale snow pillow observations were not representative of the spatial variability of the montane snowpack. Many prior studies have utilized point-scale in situ measurements (e.g., Aguado 1990; Dettinger et al. 2004; Lundquist et al. 2015), which can provide relatively long temporal records, but spatially incomplete characterizations of orographic processes. Furthermore 
a)

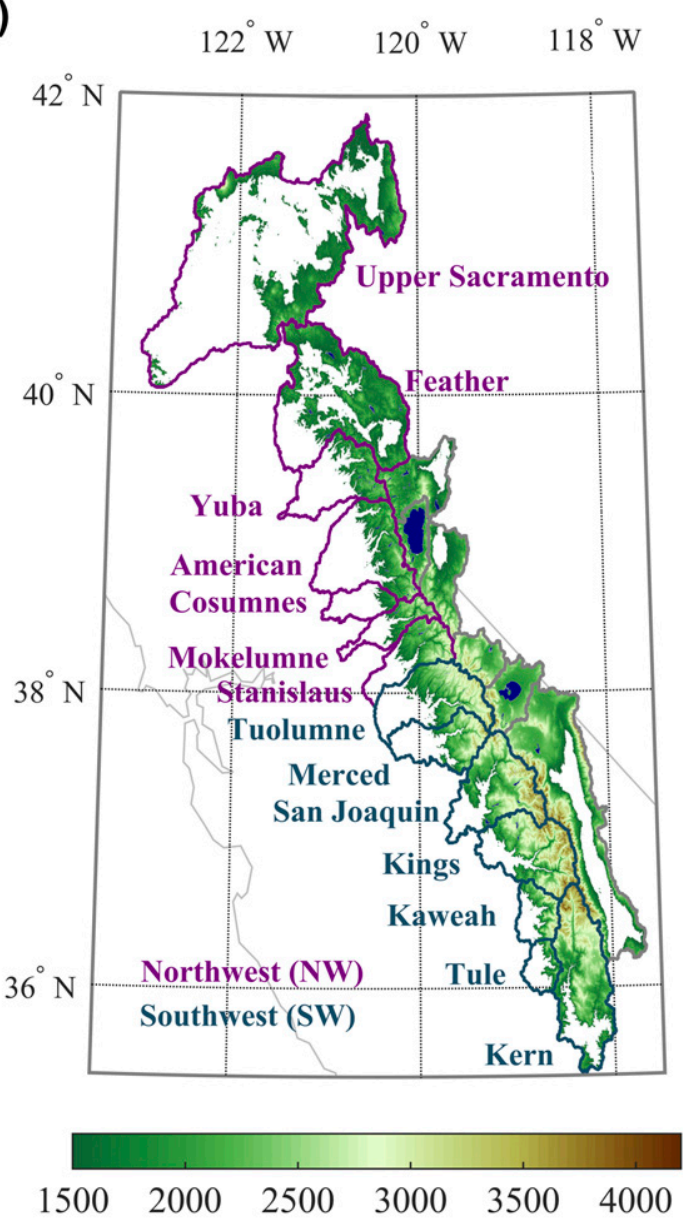

b)
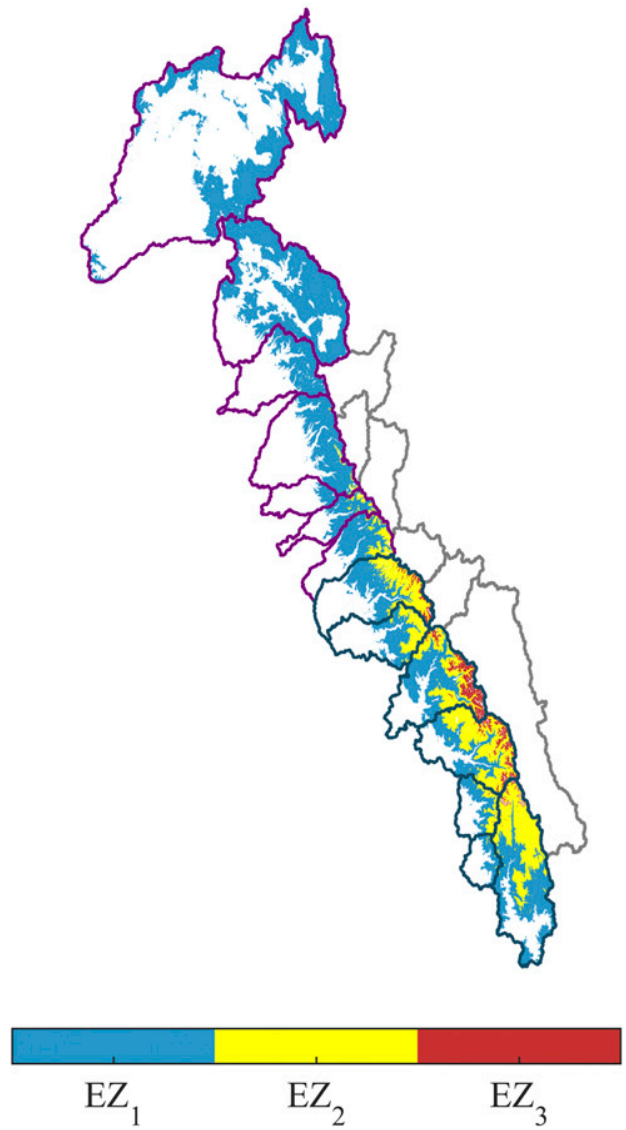

FIG. 1. (a) Elevation map (m) over the Sierra Nevada for elevations above $1500 \mathrm{~m}$ and (b) distribution of the three elevation zones $\mathrm{EZ}_{i}$ over the western basins. Basins in the NW and $\mathrm{SW}$ are identified, and the color coding is used throughout.

when gridded datasets have been used, they were generally temporally sparse and/or spatially coarse, for example, a single high-resolution snapshot in time over a limited domain (Kirchner et al. 2014) or coarseresolution (several kilometers) gridded datasets and climate models (Colle 2004; Galewsky and Sobel 2005). Coarse resolutions smooth out the heterogeneities (e.g., elevation) that control the variability of snowfall, snow states, and orographic processes over complex terrain (Leung and Ghan 1998; Cayan et al. 2008). Hence, coarse resolutions, point-scale measurements, and temporal sparseness can result in incomplete characterizations of montane snowfall.

To overcome these limitations, herein a new multidecadal, high-resolution distributed SWE reanalysis over the western Sierra Nevada (Margulis et al. 2016) was used to yield better insight into orographic enhancement, the interannual variability of orographically driven cumulative snowfall (CS) gradients, and the drivers of orographic processes in winter snowfall accumulation. Previous studies have not captured the interannual variability of orographic snowfall at the basin scale across an entire mountain range (due to limitations in data and resolution) nor have they concentrated on a thorough comparison of snowfall gradients among all windward basins in the Sierra Nevada (Fig. 1a). A detailed climatology of orographic CS gradients does not currently exist at the range scale, nor have wet-year/dryyear implications in CS gradients been explored. Herein, the CS was defined as the integrated amount of snowfall occurring over the course of the accumulation season.

This paper extends previous work to better understand the interannual and spatial variability of orographically driven snowfall gradients at high elevations across the Sierra Nevada by answering the following questions: 
1) How is orographically driven snowfall manifested across the windward (western) side of the Sierra Nevada?

2) How can the shapes of the cumulative snowfall versus elevation curves be characterized (slope, maximum, etc.) and what factors influence their shapes?

3) How and to what extent do orographic gradients vary spatially and interannually?

4) What characterizes a "wet" versus "dry" year in the Sierra Nevada in terms of orographically driven cumulative snowfall?

\section{Wintertime atmospheric conditions driving orographic enhancement}

The Sierra Nevada receives the majority of its seasonal snowfall from a few large snowstorms each year, leading to high interannual variability in CS and SWE across the range (O'Hara et al. 2009; Lundquist et al. 2015; Huning and Margulis 2017, hereafter HM17). With the rapid snowfall accumulation rates over the Sierra Nevada (Serreze et al. 2001; Lundquist et al. 2015; HM17), the heavy reliance on snowmelt across California (Downing 2015; Rosenthal and Dozier 1996; etc.), and shifts in peak streamflow/melt due to climate change (Mote et al. 2005; Barnett et al. 2005; Kapnick and Hall 2010), it is important to investigate the processes that lead to the wintertime snowfall accumulation across the Sierra Nevada, and in particular, how orography enhances snowfall accumulation.

Figure 2 presents a simplified picture of factors that tend to favor orographic enhancement during the wintertime (for reviews, see Smith 1979; Barros and Lettenmaier 1994; Roe 2005; Houze 2012). Even if all other factors promote orographic enhancement, without moisture, clouds will not form and precipitation will not occur (Fig. 2a). Stronger horizontal wind speeds perpendicular to a barrier promote greater orographic enhancement (Smith 1979; Luce et al. 2013) because they result in larger vertical uplift velocities when encountering an obstacle (Fig. 2b). Linear theory of orographic precipitation relates the precipitation rate to the moisture flux impinging on a mountain and the slope of the terrain through a simplified multiplicative relationship (e.g., Smith 1979). Basins having an increasing slope with elevation will exhibit more enhancement in general, and interannual variability of wind/moisture can increase those effects. Based on such a relationship driving orographic precipitation and the interannual variability in vapor transport among winter storms, orographic gradients between wet years and dry years are hypothesized to largely deviate from one another, with wet years exhibiting larger orographic CS gradients than dry years.
Mountains with higher peak altitudes provide greater uplift potential than lower mountains or hills (Fig. 2c). For the highest mountains, the elevation corresponding to the maximum CS $z_{\mathrm{CSmax}}$ is typically reached before the mountain peak $z_{\max }$. In lower ranges, however, $z_{\text {CSmax }}$ may occur at the peak or on the leeward side of the mountain due to spillover. While steeper slopes force uplift at a greater rate than a gradual slope, there is also greater potential for gravitational redistribution of the snow (e.g., avalanching; Grünewald et al. 2014), causing lower enhancement to be observed (Fig. 2d). Also, terrain aspects facing into the prevailing wind favor orographic enhancement as opposed to hillslopes oriented away from the prevailing wind (Fig. 2e). Downwind of a barrier, air masses warm as they descend, which reduces the relative humidity and condensation, leading to a rain shadow.

With some simplifying assumptions (e.g., uniform flow), idealized models based on linear theory (e.g., Smith and Barstad 2004) have been shown to represent the mean precipitation distribution in the northern Sierra Nevada well, but poorly represent the interannual variations due to the presence of dynamic and nonlinear factors [e.g., blocking via the Sierra barrier jet (SBJ) in Fig. 2f] (Lundquist et al. 2010). Nonetheless, linear theory presents the basic drivers of orographic precipitation: moisture and wind across a mountain barrier.

The Sierra Nevada provides a suitable domain for studying orographic enhancement because the (western) basin-average aspect values generally face into the prevailing wind with minimal upwind obstacles (Fig. 1a; Grubišić et al. 2005). Previous studies have shown the importance of atmospheric rivers (ARs; e.g., Ralph et al. 2006; Guan et al. 2010; Huning et al. 2017) and the SBJ (e.g., Lundquist et al. 2010; Hughes et al. 2012) on precipitation/snowfall patterns across the Sierra Nevada. However, investigating specific storm mechanisms or meteorological events (e.g., ARs and SBJs) is beyond the scope of this paper, which provides a seasonal study rather than an event-based analysis. Therefore, analysis considers all storm mechanisms that yield snowfall across the Sierra Nevada. Herein, large-scale atmospheric quantities such as integrated vapor transport (IVT), integrated water vapor (IWV), and zonal winds were analyzed during storm periods.

Previous studies utilizing in situ precipitation observations (Pandey et al. 1999; Dettinger et al. 2004; Lundquist et al. 2015) found that southwesterly winds tend to correspond to the largest storm events over the Sierra Nevada, while westerly/northwesterly winds generally yield greater orographic enhancement. Lundquist et al. (2015) showed that the greater elevation-dependent difference observed during northwesterly winds results from 
Less Favorable

a) Moisture Availability

Dry Air Parcel

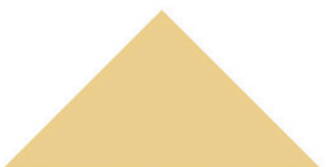

b) Wind Speed

Low Wind Speed

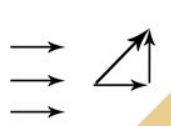

c) Mountain Height

Low Peak Elevation

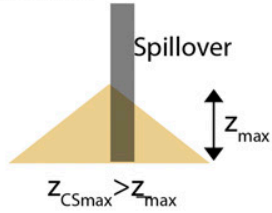

d) Terrain Slope

Gradually Sloping

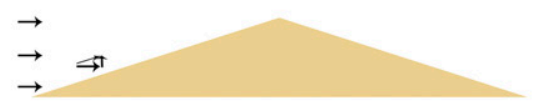

e) Direction of Prevailing Wind and Terrain Aspect (A) Misalignment

Steeply Sloped

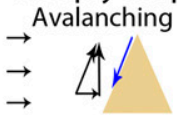

High Wind Speed

High Peak Elevation

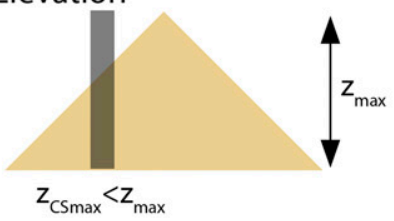

Moderately Sloped

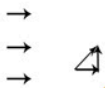

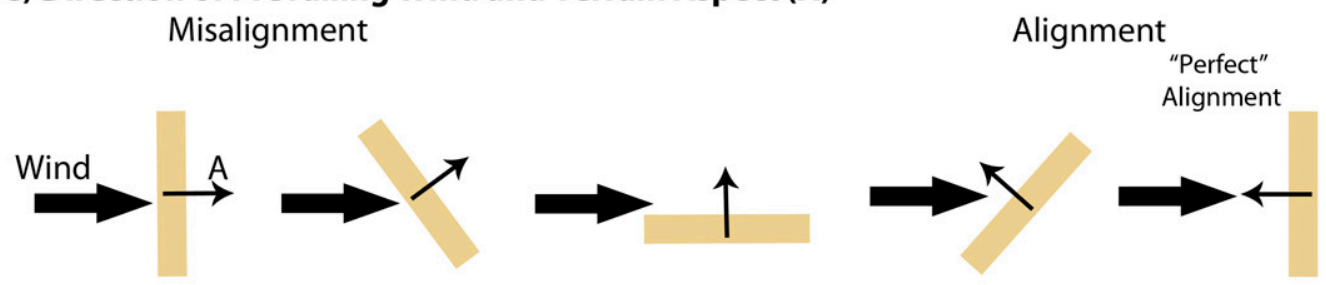

\section{f) Barrier Jet and Blocking}

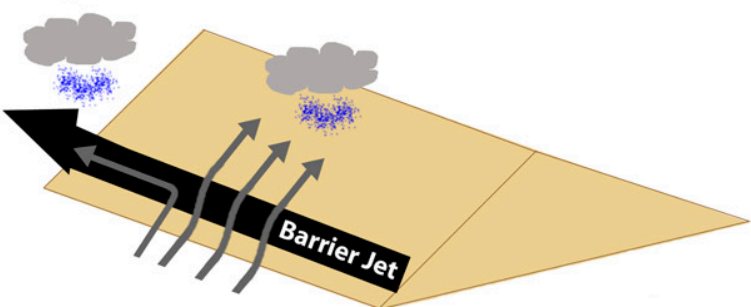

FIG. 2. Wintertime conditions promoting orographic enhancement: (a) moisture availability, (b) wind speed, (c) mountain height, (d) terrain slope, and (e) direction of prevailing wind relative to terrain aspect. Ridge height is denoted by $z_{\max }$, and $z_{\mathrm{CS} \max }$ is the elevation of maximum CS. More favorable conditions for orographic enhancement are presented moving toward the right. Terrain configuration is shown in brown. A vertical reflection of the terrain orientations in (e) would result in the same relationships as depicted here. Configurations where the aspect of the terrain points away from the prevailing direction likely result in equally unfavorable conditions for enhancement. (f) Barrier jet and blocking redistribute moisture. 
snow pillows recording increases in SWE while only minimal increases were recorded at precipitation gauges. Since climatologies in California tend to be dominated by increased total precipitation during southwesterlies, this can impact the accuracy of datasets trained on climatologies (Lundquist et al. 2015). The snowfall dataset used herein was generated with a probabilistic snow reanalysis framework (Margulis et al. 2016), which can better represent a seasonal snowfall distribution that deviates from climatology better than a statistical method solely trained on climatologies.

\section{Data and methods}

\section{a. Snowfall dataset}

For the 14 study basins along the windward side of the Sierra Nevada (Fig. 1a), snowfall was defined as increases in the 90-m daily SWE fields derived from the snow reanalysis (Margulis et al. 2016). This SWE reanalysis was generated using the process briefly described here and extensively documented by Margulis et al. (2015). An ensemble of meteorological forcings derived from phase 2 of the North American Land Data Assimilation System (NLDAS-2; Xia et al. 2012) dataset was used to drive a snow model and generate prior state estimates. These estimates were seasonally conditioned on Landsat fractional snow-covered area images within a Bayesian data assimilation framework to yield posterior estimates such as daily, 90-m SWE fields.

The land surface model used within this framework was forced with hourly meteorological input. The framework utilized a fixed air temperature threshold of $2^{\circ} \mathrm{C}$, which falls within the range suggested by Lundquist et al. (2008), to classify precipitation as either rain or snow at each hourly time step. This simplification would likely have the largest impact on lower elevations that are more prone to experiencing a mixture of rain and snow during a storm due to their warmer temperatures. Given this framework and that the analysis herein focuses on seasonal snowfall gradients, not rainfall or total precipitation gradients, an air temperature dependence was implicitly removed during snowstorms when only considering air temperatures that yielded snowfall and not melt or rainfall. The average air temperature during snowstorms was computed using daily air temperature values (from the snow reanalysis).

The SWE reanalysis was extensively verified for CS over 31 accumulation seasons in the Sierra Nevada with over 2600 station years of snow pillow observations (HM17) and for peak SWE during the same time period (Margulis et al. 2016). HM17 demonstrated that the SWE reanalysis could be utilized to examine snowfall accumulation across the Sierra Nevada by verifying the seasonal CS with observations over the range. They found a root-mean-square difference (RMSD) and mean difference (MD) of 4 and $-2 \mathrm{~cm}$, respectively, for the median seasonal CS across all stations relative to observations. A negative MD indicates an underestimation of CS relative to observed. When all stations and years were considered, the RMSD and MD were larger (12 and $-4 \mathrm{~cm}$, respectively). The RMSD and MD correspond to $15.7 \%$ and $-5.5 \%$ of the average observed CS $(\sim 77 \mathrm{~cm})$ that occurred at the stations across the Sierra Nevada during the 31 years. The bias is minimal and differences between the 90-m CS and point-scale observations are expected due to spatial disparities and representativeness issues (HM17).

\section{b. Orographic gradients}

The orographic gradient $\beta$ was defined as the rate of increase in bin-averaged CS across 100-m-elevation bins. Gradients were used to fully leverage the spatial nature of the underlying CS information by explicitly and robustly describing the distribution of CS across a watershed. Herein, snowfall is described in units of equivalent water depth and should not be confused with snow depth. Moreover, CS, as opposed to SWE on the ground at a specified time, is used to prevent the introduction of artificially large gradients if lower elevations have undergone ablation when higher elevations are continuing to accumulate SWE at a given time. CS was computed by integrating snowfall accumulated throughout the season similar to HM17. Although HM17 quantified CS over the entire Sierra Nevada, they focused on accumulation rates, while orographic CS gradients and enhancement across the windward basins were investigated herein.

\section{CONSTRUCTION OF OROGRAPHIC CS CURVES}

A minimum daily snowfall $S$ of $0.254 \mathrm{~cm}$ (Serreze et al. 2001) was used to remove negligible increases in SWE (i.e., $S=\Delta S W E \geq 0.254 \mathrm{~cm}$ ). To prevent exaggerating orographic gradients with the inclusion of pixels with very low or no seasonal snowfall accumulation, a "filtering" approach was used. Only pixels $j$ were considered that received at least $2 \mathrm{~cm}$ of CS by the end of a given season as defined by

$$
\mathrm{CS}_{j}=\sum_{t=1 \mathrm{Nov}}^{\mathrm{DOP}} S_{j}(t) \geq 2 \mathrm{~cm} .
$$

Analysis was performed at high elevations (above the average $1500 \mathrm{~m}$ snow line) during the cold season, from November through the basin-average day-of-peak (DOP) SWE [as denoted in Eq. (1)], for each watershed over 31 water years (WYs; from 1 October to 30 September) 1985-2015. As shown in Fig. 1, the Sierra 
Nevada was divided into the northwest (NW) and southwest (SW) to elucidate the distinct precipitation regimes of the northern Sierra Nevada (which tends to receive more precipitation) and the higher-elevation southern Sierra Nevada. All land pixels in the western (W) basins (Fig. 1a) were considered herein. The gridded data were divided into 100-m-elevation bins, where bins with $<0.5 \%$ of the total number of pixels in the basin (above $1500 \mathrm{~m}$ ) were neglected to avoid relatively few pixels from dictating orographic relationships (Grünewald et al. 2014).

Based on the combination of the seasonal CS and elevation bin criteria above, different numbers of pixels and bins were used annually in computations. This "filtering" approach was used to focus on CS gradients only as opposed to total precipitation. Averaged across all years and basins, this results in $\sim 3 \%$ difference or less between the orographic gradients diagnosed using all pixels (i.e., "unfiltered" approach) versus only snowcovered pixels (i.e., "filtered" approach) relative to the unfiltered 31-yr average orographic gradient values. Although the percent difference is small, the filtering of nonsnowy pixels prevents exaggerating orographic CS gradients by removing negligible values (typically at the lowest elevations). Neglecting nonsnowy pixels acknowledges that the gradient is constructed where snow exists following fluctuations in the snow line above $1500 \mathrm{~m}$.

Since a single linear fit does not necessarily describe the orographic snowfall accumulation observed across different regimes (Grünewald et al. 2014), a piecewise least squares regression, using a maximum of three line segments, was applied to the CS-elevation curves. These elevational relationships for individual basins were derived using mean values within each bin. The segments were fit to the data between 1) the lowest elevation and $\sim 2500 \mathrm{~m}, 2) \sim 2500 \mathrm{~m}$ and the elevation corresponding to the 31 -yr average maximum CS $\bar{z}_{\mathrm{CSmax}}$, and 3) $\bar{z}_{\text {CSmax }}$ and the maximum elevation $z_{\max }$. Not all three segments (within elevation zones $\mathrm{EZ}_{i}$, where $i=1-3)$ exist for each basin; however, where possible, the 31-yr average orographic CS gradient is denoted as $\bar{\beta}\left(\mathrm{EZ}_{i}\right)$. The approximate upper bound of $2500 \mathrm{~m}$ was chosen for $\mathrm{EZ}_{1}$ because it captures the linear relationship at the lowest elevations considered. While nearly all basins span these elevations, some do not have a noticeable fraction of area above $2500 \mathrm{~m}$ (based on the $0.5 \%$ threshold described above). Therefore, the elevation of the binned data with a mean value closest to $2500 \mathrm{~m}$ was used as the upper bound of $\mathrm{EZ}_{1}$. Figure $1 \mathrm{~b}$ shows the spatial distribution of the elevation zones. Elevation maps (Fig. 1) and other physiographic characteristics were derived from Margulis et al. (2016).

\section{c. Wet- and dry-year selection}

An important missing piece in understanding the interannual variability of $\mathrm{CS}$ is a thorough assessment of wet-year and dry-year orographic CS and how synoptic atmospheric conditions in the Sierra Nevada contribute to orographic enhancement at the basin scale. To examine potential drivers of orographic enhancement (moisture transport, wind speed/direction, etc.) and understand the interannual variability of orographically driven snowfall, the 31 years were subdivided into wet and dry years following HM17. The same years were analyzed herein. Wet years include WYs 1986, 1993, 1995, 1998, 2005, 2006, 2008, and 2011 and dry years include WYs 1987, 1988, 1990, 1992, 1994, 2001, 2007, and 2012-15. The classifications were defined based on the integrated basin-averaged $\mathrm{CS}$ across the range for consistency across all basins. Although the number of wet years (8) and dry years (11) differ, the orographic features remain similar when an equal number of wet and dry years are analyzed.

\section{d. Orographic enhancement}

Herein, "orographic enhancement" corresponds to conditions where CS increases with elevation or conditions where higher values of the CS gradients were observed relative to lower ones. This latter definition can be applied to specific years, elevation zones, or regions. Furthermore, for each EZ, the degree of orographic enhancement exhibited during wet years relative to dry years was defined as the ratio $\bar{\beta}_{w} / \bar{\beta}_{d}$, where $\bar{\beta}_{w}$ and $\bar{\beta}_{d}$ are the average wet-year and dry-year gradients, respectively.

\section{e. Snowstorm conditions}

\section{1) SNOWSTORM CHARACTERIZATION}

The basinwide snowstorms identified by HM17 were used herein to investigate potential synoptic storm features driving the interannual variability of orographic snowfall processes and orographic enhancement. Using the SWE reanalysis, HM17 defined snowstorms to be those days during the accumulation season that contributed at least $1 \%$ of the integrated seasonal CS volume across a basin at the highest elevations (i.e., elevations above the 75th percentile). Consecutive days satisfying this condition were grouped into a single event. Their approach was designed to capture the events that most significantly drive CS during the winter. Those same snowstorm periods were used here. Basinwide snowstorms account for differences in storm track location/ timing and local interactions (HM17). The "leading event" for a given year was defined as the snowstorm that yielded the largest integrated CS volume over a basin. 


\section{2) SYNOPTIC ATMOSPHERIC CONDITIONS}

Synoptic atmospheric conditions during snowstorm events were diagnosed with the North American Regional Reanalysis (NARR; Mesinger et al. 2006). NARR was selected for its relatively high resolution (3-hourly, $32 \mathrm{~km}$ ). In addition, the near-surface fields used to force the land surface model in Margulis et al. (2016) were taken from NLDAS-2, which derives several of its meteorological fields from NARR. The SWE reanalysis was forced by precipitation derived from NLDAS-2 [which was based on observational data from the Climate Prediction Center (CPC) precipitation gauge network]. NARR was used herein to diagnose atmospheric fields; however as Hughes et al. (2012) showed, NARR may not fully represent features such as the SBJ.

NARR grid cells overlapping each watershed were identified and atmospheric variables were averaged to characterize basinwide atmospheric dynamics. IVT and IWV, derived from NARR, were investigated herein following previous studies (e.g., Rutz et al. 2014; Guan and Waliser 2015) that examined the relationship between these atmospheric quantities and precipitation in the western United States. IVT, which accounts for both the wind field (direction and speed) and humidity in the overlying atmosphere, was computed from the surface to $100 \mathrm{hPa}$ to characterize typical snowstorm conditions. Based on Lavers et al. (2012), the magnitude of the IVT vector is given by

$$
\begin{aligned}
& \operatorname{IVT}\left(\mathrm{kg} \mathrm{m}^{-1} \mathrm{~s}^{-1}\right) \\
& =\sqrt{\left(\frac{1}{g} \int_{p_{\mathrm{scc}}}^{10000 \mathrm{~Pa}} q u d p\right)^{2}+\left(\frac{1}{g} \int_{p_{\mathrm{sfc}}}^{10000 \mathrm{~Pa}} q v d p\right)^{2}},
\end{aligned}
$$

where $g$ is the acceleration due to gravity $\left(\mathrm{m} \mathrm{s}^{-2}\right), p_{\text {sfc }}$ is the surface pressure $(\mathrm{Pa}), q$ is the specific humidity $\left(\mathrm{kg} \mathrm{kg}^{-1}\right), u$ and $v$ are the zonal and meridional wind $\left(\mathrm{m} \mathrm{s}^{-1}\right)$, and $p$ is the pressure. The direction of the IVT vector is determined using geometric relationships. The magnitude of the horizontal vapor transport at each atmospheric level is defined as

$$
\mathrm{VT}\left(\mathrm{kg} \mathrm{kg}^{-1} \mathrm{~m} \mathrm{~s}^{-1}\right)=\sqrt{\left(\frac{1}{g} q u\right)^{2}+\left(\frac{1}{g} q v\right)^{2}} .
$$

IWV was computed between the same levels used for IVT. Since westerly winds prevail across the western United States, Luce et al. (2013) showed that orographic precipitation could be related to zonal winds at $700 \mathrm{hPa} u_{700}$ across mountainous terrain. Although not shown, statistically significant positive correlations $(p<0.05)$ between $u_{700}$ and the wind speed at the surface and at $700 \mathrm{hPa}$ during snowstorms were found across the Sierra Nevada using NARR. The abovementioned studies and linear theory motivate the investigation of IVT, IWV, and $u_{700}$ to better understand orographic CS distributions.

\section{Results and discussion}

\section{a. Seasonal CS and snowstorm air temperature}

Figure 3 shows the elevational distribution of the correlation between average seasonal CS and average air temperature during storms across all pixels (binned) each year. Bins with statistically significant correlations $(p<0.05)$ are shaded gray. Negative correlation values exist at the lowest elevations and the magnitude of the correlation decreases (and $p$ values increase) with elevation until correlation coefficients become positive at higher elevations. Figure 3 a demonstrates that by focusing on snowfall and temperatures that yield snowfall, an elevational dependence between the CS and air temperature during snowstorms is implicitly removed. Filtering (described above) removes the statistical significance that is mainly observed at the lowest elevations in $\mathrm{EZ}_{1}$ without any filtering applied (i.e., Fig. 3b). Note that while nearly all of the elevation bins in Cosumnes indicate that a statistically significant correlation exists between CS and air temperature (Fig. 3a), the correlations across the basin do not greatly vary in magnitude. Since similar sensitivities of CS to temperature are shown across the basin, temperature may not greatly control $\bar{\beta}$. Correlations are generally not statistically significant across elevations when considering all 31 years for nearly all basins. Hence, temperature is not expected to have a significant impact on the mean gradients, although the correlations between CS and air temperature vary with elevation. Similar conclusions are reached regarding wet years across the mountain range (not shown).

Considering dry years and performing similar elevational analysis (not shown) indicates that statistically significant correlations between CS and air temperature occur across a greater number of elevation bins. This is observed particularly in the NW (i.e., $\mathrm{EZ}_{1}$ ), where the average difference in correlation coefficients across basins is 0.23 . It is therefore expected that temperature likely impacts $\bar{\beta}_{d}$ primarily in $\mathrm{EZ}_{1}$ in the NW.

Note, however, that a distinct trend between wet/dry years and cool/warm storms was not observed across the western Sierra Nevada when a bulk temperature comparison was performed (not shown). Recall that analysis was only conducted for snowfall as opposed to total precipitation. The absence of snowfall therefore does not indicate an absence of rainfall or precipitation during a season. Also, average snowstorm temperatures were utilized rather than including temperature from all days 
a)
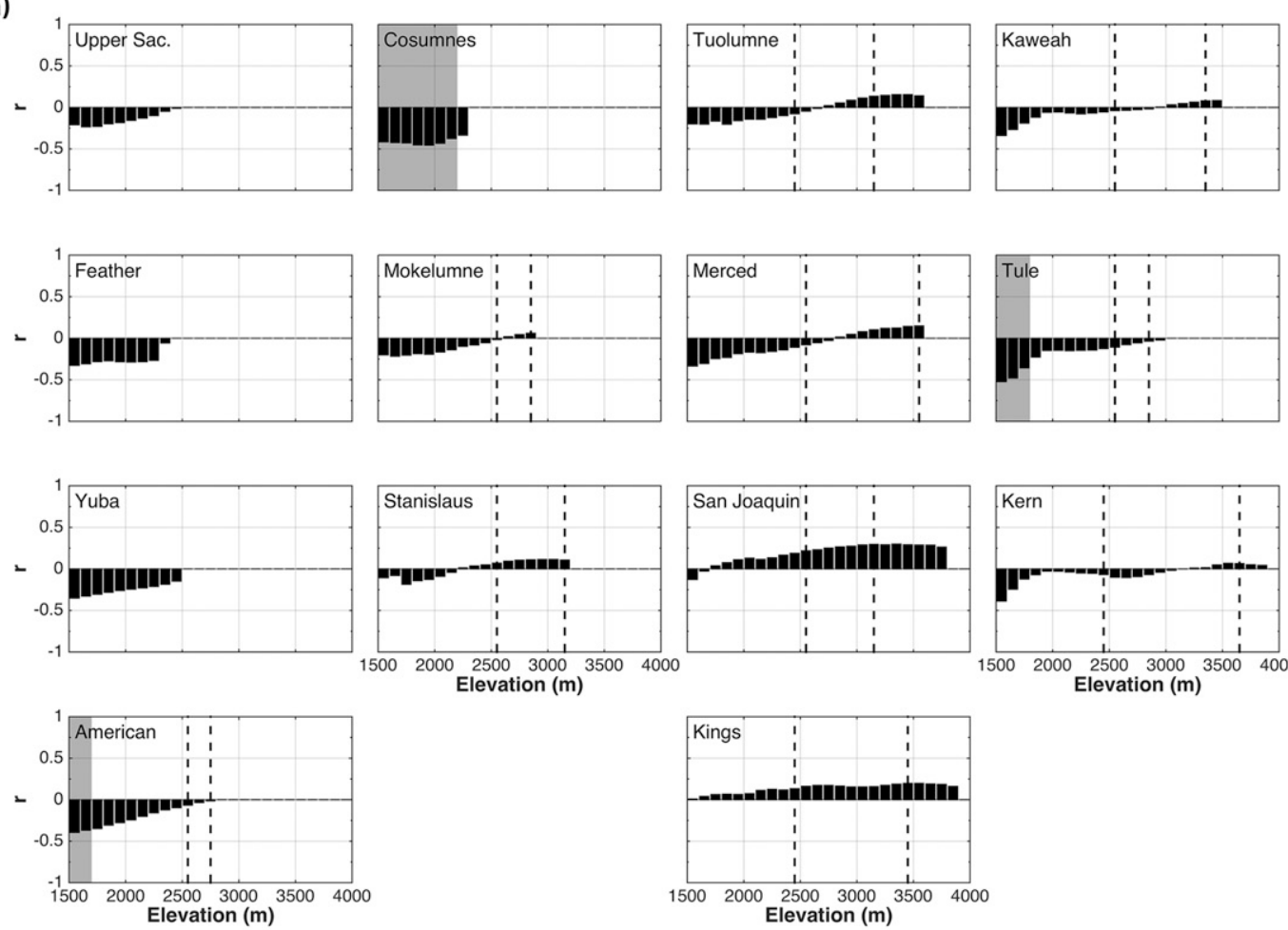

b)
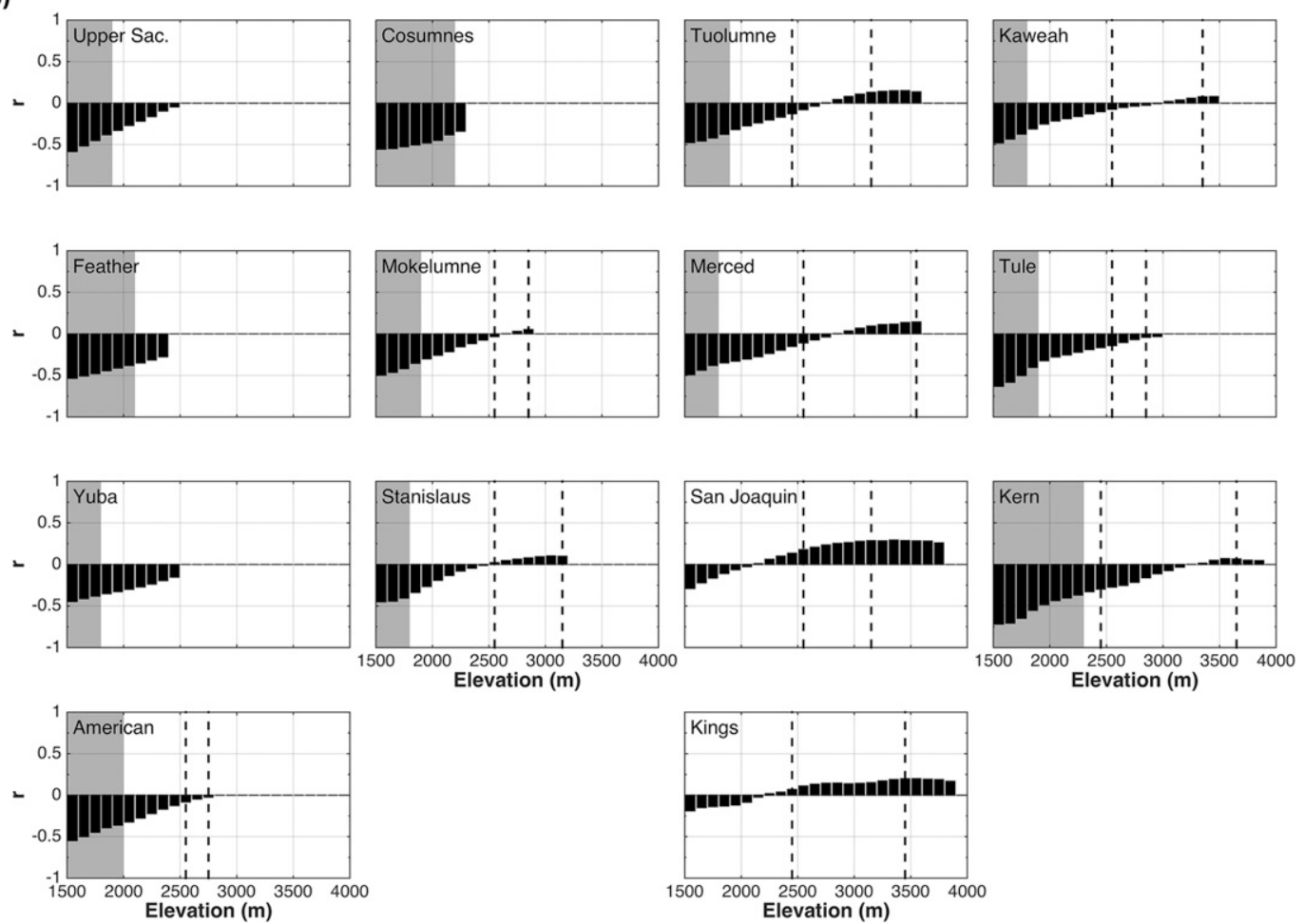

FIG. 3. Elevational distribution of the correlation coefficient $r$ between average storm temperature and average CS across the 31 years for the (a) filtered and (b) unfiltered approaches. Shaded regions indicate statistically significant correlations. Vertical lines demarcate the upper and lower elevation bins for $\mathrm{EZ}_{2}$. 

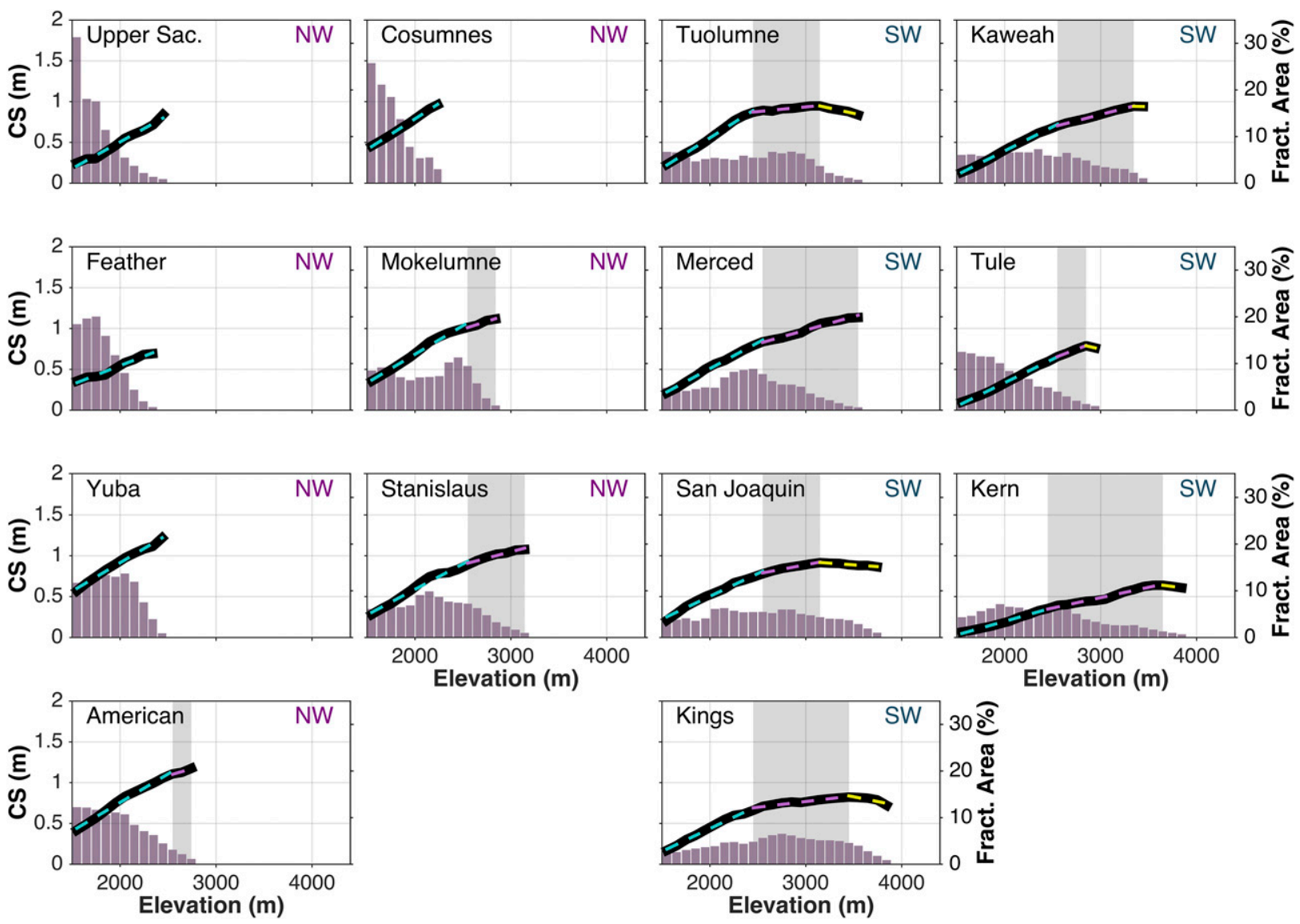

FIG. 4. Elevational distribution of CS where the solid line indicates the 31-yr average, and the dashed lines correspond to the lines of best fit for each elevation zone. The histogram displays the (static) elevational distribution of pixels as a fraction of the total area above $1500 \mathrm{~m}$. Each bar represents $>0.5 \%$ of the total area, and $\mathrm{EZ}_{2}$ is shaded gray.

during the winter or water year in the analysis. Daily snowstorm temperatures were used as opposed to subdaily temperatures, which may rapidly fluctuate during a storm with the movement of the snow line. If a range of air temperatures over which precipitation was partitioned into a mixture of rain and snow were used within the snow model framework, differences in the relationship between CS and temperature shown here may exist.

\section{b. Shape of orographic CS curves}

To characterize the general shape of the CS-elevation curves, the 31-yr average (black curve) for each of the basins (Fig. 4) is first examined. For reference, the histogram indicates the (static) elevational distribution of area within each basin. As demonstrated in Fig. 4, NW basins are characterized by increasing orographic curves that reach their maximum in their highest elevation bin. They do not exhibit a negative slope after a maximum is reached like the majority of higher-elevation SW basins. Only American, Mokelumne, and Stanislaus in the NW extend beyond $\mathrm{EZ}_{1}$ and into $\mathrm{EZ}_{2}$ (Figs. 1b, 4). At the lowest elevations, every basin has a strong, linearly increasing CS-elevation relationship. By definition, CS continues to increase linearly with elevation for each of the basins in $\mathrm{EZ}_{2}$ (shaded gray; Fig. 4). Only six SW basins have orographic curves that extend into $\mathrm{EZ}_{3}$ (Figs. 1b, 4), where each exhibits a negative slope. As such, the basinwide shapes of the climatological CS-elevation curves can be classified into two groups: 1) increasing and 2) increasing to a maximum and then decreasing.

As demonstrated in Fig. 4, the elevation of the (31-yr) maximum CS occurs at the highest elevations for all NW basins and Merced. Consequently, the elevation of $\bar{z}_{\mathrm{CSmax}}$ for the remaining six SW basins is governed by other physical processes that dominate the higher elevations. In these six $\mathrm{SW}$ basins, $\bar{z}_{\mathrm{CSmax}}$ ranges from $\sim 2850 \mathrm{~m}$ (Tule) to $3650 \mathrm{~m}$ (Kern), which is similar to values found in literature [e.g., $3300 \mathrm{~m}$ (Kirchner et al. 2014); $\sim 2000-3000 \mathrm{~m}$ (subcatchment scale) and up to $\sim 3400 \mathrm{~m}$ (transect scale; Grünewald et al. 2014)]. Although values of $z_{\text {CSmax }}$ have been theoretically estimated (e.g., Alpert 1986) or observed, previous studies 
a)

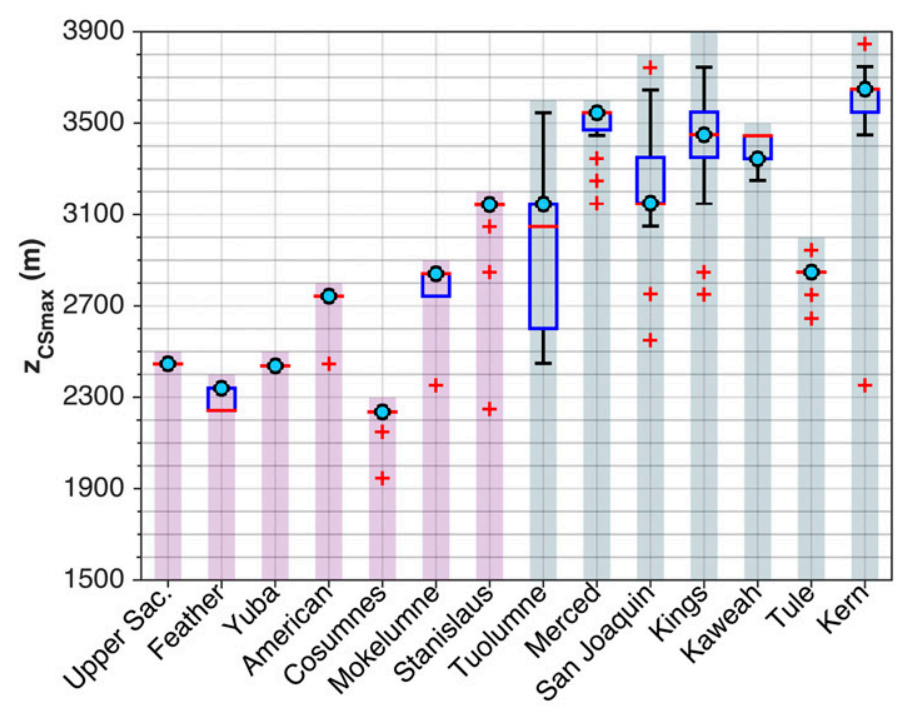

b)
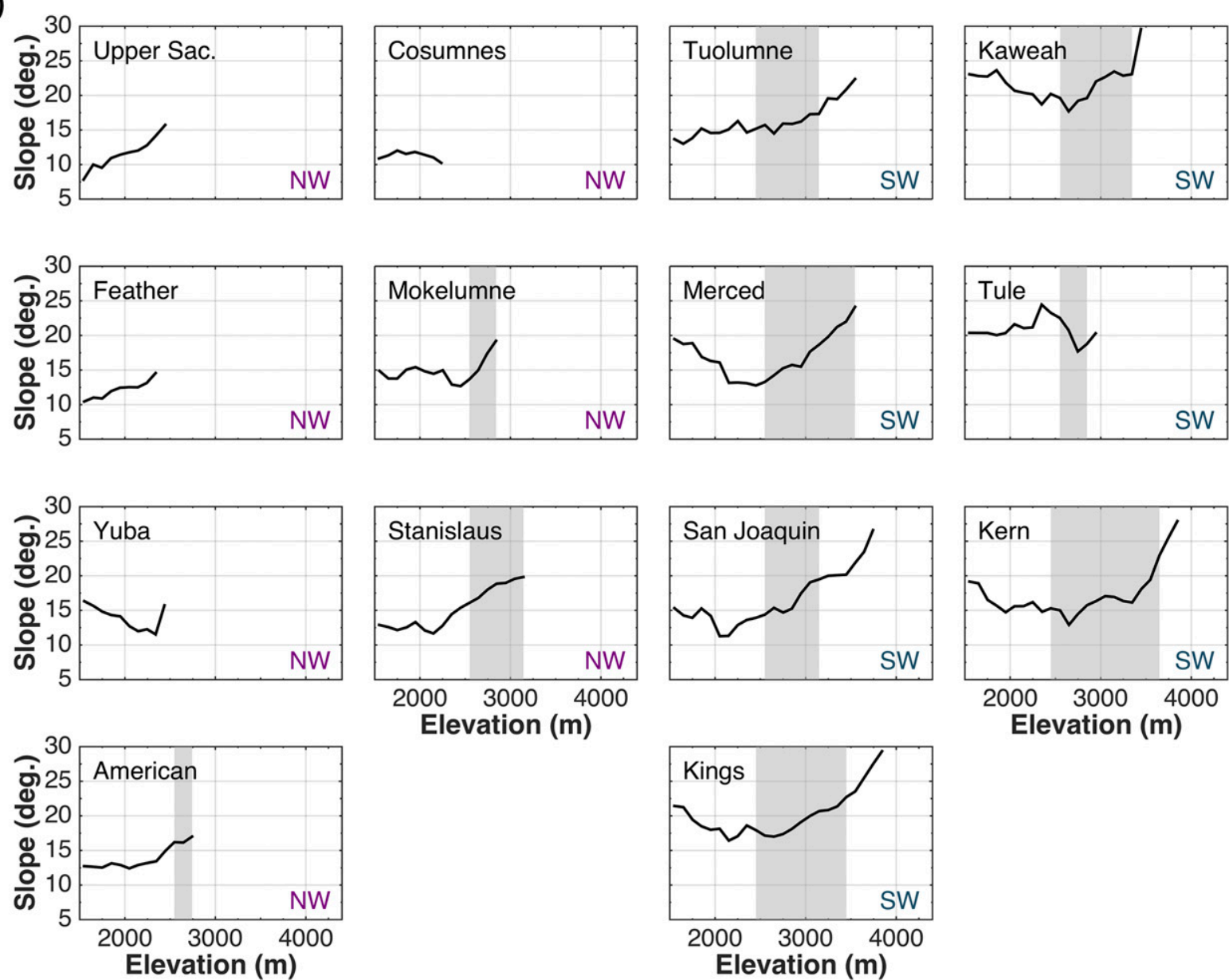

FIG. 5. Distribution of (a) $z_{\mathrm{CSmax}}$ and (b) the slope of the terrain for each basin. In (a), the red lines and + symbols demarcate the median and outliers, respectively. Circles indicate $\bar{z}_{\text {CSmax }}$. Shaded bars span the elevational range for each basin, extending from $1500 \mathrm{~m}$ to the upper bound of the $100-\mathrm{m}$ bin containing its maximum elevation $z_{\max }$. Elevation zone $\mathrm{EZ}_{2}$ is shaded gray in (b). 
TABLE 1 . The 31-yr, wet-year, and dry-year averaged orographic gradients $\left(\bar{\beta}, \bar{\beta}_{w}\right.$, and $\bar{\beta}_{d}$, respectively) and the relative orographic enhancement $\bar{\beta}_{w} / \bar{\beta}_{d}$ for each basin and EZ. Regional/range averages were computed using the tabulated basin values. Values in EZ are the same for the SW and W since NW basins do not extend into this zone.

\begin{tabular}{|c|c|c|c|c|c|c|c|c|c|c|c|c|}
\hline \multirow[b]{2}{*}{ Basin } & \multicolumn{3}{|c|}{$\bar{\beta}(\mathrm{cm}$ per $100 \mathrm{~m})$} & \multicolumn{3}{|c|}{$\bar{\beta}_{w}(\mathrm{~cm}$ per $100 \mathrm{~m})$} & \multicolumn{3}{|c|}{$\bar{\beta}_{d}(\mathrm{~cm}$ per $100 \mathrm{~m})$} & \multicolumn{3}{|c|}{$\bar{\beta}_{w} / \bar{\beta}_{d}$} \\
\hline & $\mathrm{EZ}_{1}$ & $\mathrm{EZ}_{2}$ & $\mathrm{EZ}_{3}$ & $\mathrm{EZ}_{1}$ & $\mathrm{EZ}_{2}$ & $\mathrm{EZ}_{3}$ & $\mathrm{EZ}_{1}$ & $\mathrm{EZ}_{2}$ & $\mathrm{EZ}_{3}$ & $\mathrm{EZ}_{1}$ & $\mathrm{EZ}_{2}$ & $\mathrm{EZ}_{3}$ \\
\hline Upper Sacramento & 6.5 & - & - & 8.6 & - & - & 4.5 & - & - & 1.9 & - & - \\
\hline Feather & 4.6 & - & - & 5.4 & - & - & 3.2 & - & - & 1.7 & - & - \\
\hline Yuba & 7.0 & - & - & 8.5 & - & - & 4.9 & - & - & 1.7 & - & - \\
\hline American & 7.0 & 3.5 & - & 9.4 & 5.3 & - & 4.5 & 2.5 & - & 2.1 & 2.1 & - \\
\hline Cosumnes & 7.5 & - & - & 9.2 & - & - & 5.5 & - & - & 1.7 & - & - \\
\hline Mokelumne & 7.0 & 3.8 & - & 9.7 & 5.6 & - & 4.6 & 2.0 & - & 2.1 & 2.8 & - \\
\hline Stanislaus & 6.2 & 3.1 & - & 9.1 & 4.4 & - & 3.5 & 1.9 & - & 2.6 & 2.3 & - \\
\hline Tuolumne & 7.4 & 1.1 & -2.6 & 11.8 & 0.8 & -3.5 & 3.7 & 1.3 & -1.2 & 3.2 & 0.6 & 2.9 \\
\hline Merced & 6.4 & 3.3 & - & 10.0 & 4.1 & - & 3.6 & 2.5 & - & 2.8 & 1.7 & - \\
\hline San Joaquin & 5.6 & 2.2 & -0.8 & 8.6 & 3.5 & -1.2 & 3.2 & 1.4 & -0.7 & 2.7 & 2.5 & 1.6 \\
\hline Kings & 5.6 & 1.4 & -2.3 & 9.3 & 2.1 & -3.8 & 2.9 & 0.9 & -0.9 & 3.2 & 2.4 & 4.1 \\
\hline Kaweah & 5.9 & 3.0 & -0.3 & 9.7 & 4.3 & -0.4 & 3.1 & 2.2 & 0.7 & 3.1 & 1.9 & -0.5 \\
\hline Tule & 5.8 & 4.5 & -2.8 & 10.3 & 6.6 & -4.3 & 3.0 & 2.6 & -1.2 & 3.5 & 2.5 & 3.7 \\
\hline Kern & 3.3 & 2.5 & -1.6 & 6.0 & 4.2 & -3.4 & 1.9 & 1.4 & -0.1 & 3.2 & 3.0 & 49.0 \\
\hline NW average & 6.6 & 3.4 & - & 8.6 & 5.1 & - & 4.4 & 2.1 & - & 2.0 & 2.4 & - \\
\hline SW average & 5.7 & 2.6 & -1.7 & 9.4 & 3.7 & -2.8 & 3.1 & 1.8 & -0.6 & 3.1 & 2.1 & 10.1 \\
\hline $\mathrm{W}$ average & 6.1 & 2.9 & -1.7 & 9.0 & 4.1 & -2.8 & 3.7 & 1.9 & -0.6 & 2.5 & 2.2 & 10.1 \\
\hline
\end{tabular}

have not shown whether these elevations were relatively constant for basins over long records (i.e., multiple decades) as shown in Fig. 5a. Given the geometry of a basin, $z_{\mathrm{CSmax}}$ has low interannual variability and is relatively constant at the seasonal scale. It is hypothesized that a combination of factors dictate $z_{\mathrm{CSmax}}$ and the negative values of orographic gradients for the six SW basins in $\mathrm{EZ}_{3}$, including a limited moisture-holding capacity at high altitudes that reduces the amount of snowfall that occurs (i.e., atmospheric moisture is exhausted; e.g., Kirchner et al. 2014). Gravitational processes (Grünewald et al. 2014) and wind redistribution also contribute to negative gradients in $\mathrm{EZ}_{3}$ across these highest elevations that are more exposed and less vegetated (Margulis et al. 2016) and often have the steepest (bin averaged) terrain within a basin (Fig. 5b). Slope varies with elevation (nonmonotonically) and therefore contributes to variability in the CS enhancement across the domain. Since the gradients observed in $\mathrm{EZ}_{3}$ were constructed with fewer pixels, primary focus is on $\mathrm{EZ}_{1}$ and $\mathrm{EZ}_{2}$ below.

\section{c. Characterization of orographic gradients and enhancement}

\section{1) LONG-TERM AVERAGE OROGRAPHIC GRADIENTS}

Overall, the largest orographic gradients occur in $\mathrm{EZ}_{1}$ across the Sierra Nevada (Table 1, Fig. 4). Table 1 indicates that five basins have 31-yr averaged gradients greater than or equal to $7.0 \mathrm{~cm}$ SWE per $100-\mathrm{m}$ elevation in $\mathrm{EZ}_{1}$, with the steepest gradient found in Cosumnes $(7.5 \mathrm{~cm}$ per $100 \mathrm{~m})$. Tuolumne and Kings display the smallest 31-yr average gradients in $\mathrm{EZ}_{2}$ of $\sim 1.1-1.4 \mathrm{~cm}$ per $100 \mathrm{~m}$, likely due to localized rain shadow effects. Although the orographic curves continue to increase from $\mathrm{EZ}_{1}$ to $\mathrm{EZ} Z_{2}$, a reduction in the rate of orographic enhancement [i.e., $\bar{\beta}\left(\mathrm{EZ}_{2}\right)<\bar{\beta}\left(\mathrm{EZ}_{1}\right)$ ] is observed. The values of $\bar{\beta}\left(\mathrm{EZ}_{1}\right)$ are from $\sim 1.3$ (Tule) to 6.5 (Tuolumne) times larger than $\bar{\beta}\left(\mathrm{EZ}_{2}\right)$. On average, this ratio is $\sim 2.5$. The 31-yr average gradients in $\mathrm{EZ}_{3}$ range from -0.3 (Kaweah) to $-2.8 \mathrm{~cm}$ per $100 \mathrm{~m}$ (Tule).

Based on the 31-yr averages in $\mathrm{EZ}_{1}$ and $\mathrm{EZ}_{2}$ in Table 1, the NW exhibits greater orographic enhancement than the SW basins by $\sim 1 \mathrm{~cm}$ per $100 \mathrm{~m}$. However, when comparing individual basins in the two regions, $\bar{\beta}\left(\mathrm{EZ}_{1}\right)$ can differ on the order of $4 \mathrm{~cm}$ per $100 \mathrm{~m}$. Although the magnitudes of the orographic gradients tend to decrease with elevation from $\mathrm{EZ}_{1}$ to $\mathrm{EZ}_{3}$, this does not always hold for an individual year (Fig. 6).

\section{2) INTERANNUAL VARIABILITY OF OROGRAPHIC GRADIENTS}

Over the 31 years of orographic gradients presented in Fig. 6, negative slopes did not occur at the lowest elevations (Fig. 6a). Although uncommon, some basins/years exhibited small negative gradients in $\mathrm{EZ}_{2}$ (Fig. 6b) as well as positive gradients in $\mathrm{EZ}_{3}$ (Fig. 6c). Across all years in Fig. 6, the steepest (magnitude) gradient for each basin ranged from 8.8 (Feather, WY 2006) to $15.0 \mathrm{~cm}$ per $100 \mathrm{~m}$ (Cosumnes, WY 1986) in $\mathrm{EZ}_{1}$, from 5.6 (Kings, WY 1986) to $15.2 \mathrm{~cm}$ per $100 \mathrm{~m}$ (Tule, WY 1986) in $\mathrm{EZ}_{2}$, and from -2.7 (San Joaquin, WY 1995) to $-7.6 \mathrm{~cm}$ per $100 \mathrm{~m}$ 
a)

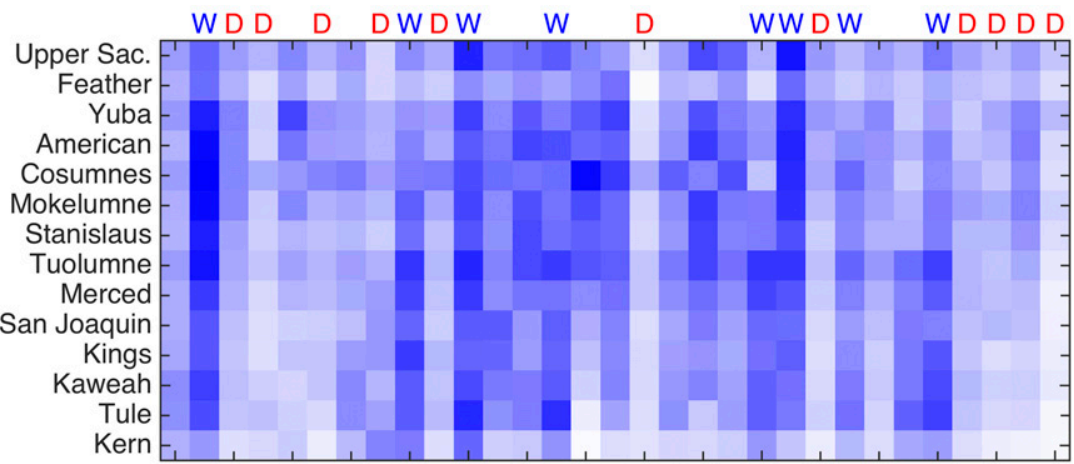

b)

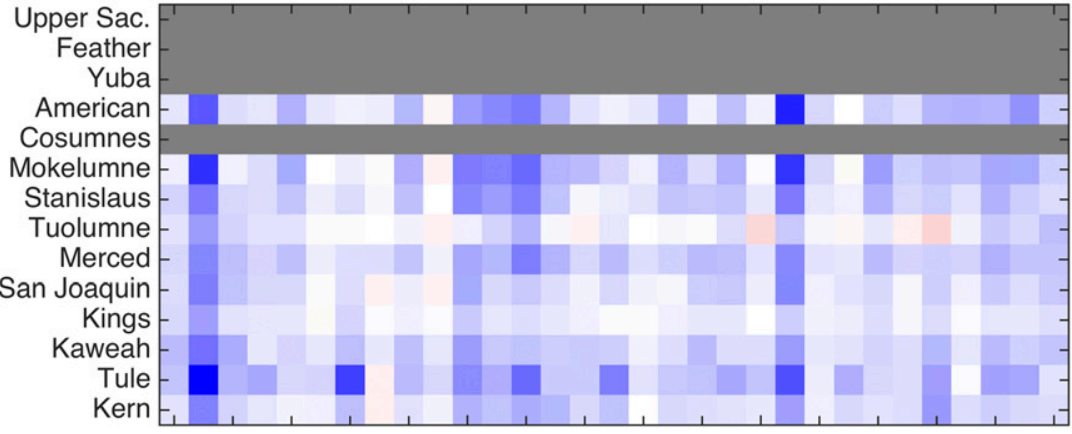

c)

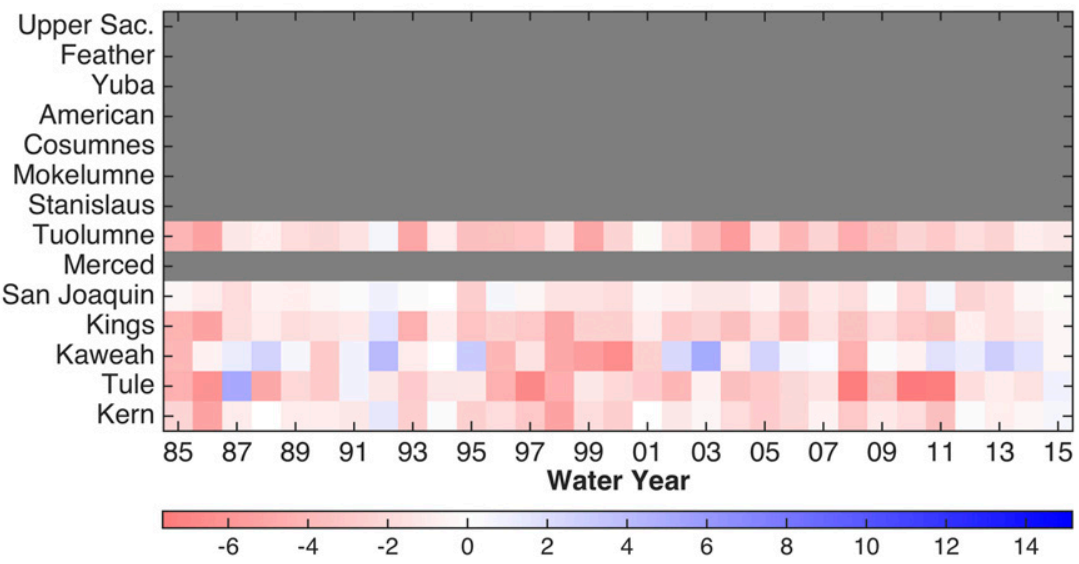

FIG. 6. Basinwide CS gradients (cm per $100 \mathrm{~m}$ ) for (a) $\mathrm{EZ}_{1}$, (b) $\mathrm{EZ}_{2}$, and (c) $\mathrm{EZ}_{3}$ over the 31 years. Wet and dry years are denoted with " $W$ " and " $D$," respectively.

(Tule, WY 2010) in $\mathrm{EZ}_{3}$. Approximately $58 \%$ of the steepest gradients for each basin across $\mathrm{EZ}_{1}$ and $\mathrm{EZ}_{2}$ exceeded $10 \mathrm{~cm}$ per $100 \mathrm{~m}$. About $63 \%$ of the gradients with the smallest magnitude for each basin in these two zones had magnitudes less than $1 \mathrm{~cm}$ per $100 \mathrm{~m}$ (Figs. 6a,b). Further discussion of the wet-year and dry-year gradients and their ratios (i.e., $\bar{\beta}_{w} / \bar{\beta}_{d}$ ) is presented below.

\section{d. What makes a wet versus dry year in the Sierra Nevada?}

HM17 showed that, on average, 11 snowstorms occur annually in the Sierra Nevada and their characteristics determine a wet versus dry year. They found that the number of snowstorms per year and their total duration explain $\sim 43 \%$ and $\sim 70 \%$ of the variance in integrated CS across the mountain range, respectively. Hence, the snowstorm periods from HM17 were used below to understand how synoptic features drive variability in CS gradients.

\section{1) REPRESENTATIVE AVERAGE SNOWSTORM CONDITIONS}

Figure 7 compares the seasonal and average snowstorm characteristics of two representative basins, Mokelumne (NW) and Kaweah (SW), during WYs 1986 and 2015. The basins exhibit the typical CS-elevation relationships and snowstorm characteristics observed in the NW and SW. 
These two years generally represent those with the greatest and least orographic enhancement (i.e., highest/ lowest gradients) over the range in $\mathrm{EZ}_{1}$ (Fig. 6a) and correspond to a wet and dry year, respectively. Figure 7a depicts the elevational variation of CS during WYs 1986 (blue) and 2015 (red) for both basins and indicates that a stark contrast between wet-year and dry-year orographic CS gradients exists. WY 1986 yielded orographic gradients of 14.5 (Mokelumne) and $11.4 \mathrm{~cm}$ per $100 \mathrm{~m}$ (Kaweah) in EZ (as shown in Figs. 6a, 7a) while WY 2015 only yielded 2.7 (Mokelumne) and $1.4 \mathrm{~cm}$ per $100 \mathrm{~m}$ (Kaweah). Hence, WY 1986 had orographic gradients $\sim 5.4$ and 8.5 times larger than during 2015 for Mokelumne and Kaweah, respectively. Interannual variability of orographic CS gradients is further examined below.

Synoptic features (i.e., $u_{700}$, IVT, and IWV) are presented in Figs. 7b-d for the average snowstorm and leading snowstorm conditions during WYs 1986 and 2015 across Mokelumne and Kaweah. Although synoptic conditions vary among basins, the differences between a year with strong versus weak orographic enhancement are highlighted. Zonal wind speeds are higher in both basins averaged across storms (i.e., seasonal scale) and at the leading snowstorm scale during the wet year (Fig. 7b). Similarly, IVT is larger in 1986 than in 2015 (Fig. 7c) for both basins. While $u_{700}$ and IVT are generally larger during wet years than dry years, Fig. $7 \mathrm{~d}$ suggests that IWV, in the absence of considering winds and transport, is not as strong of an indicator of wet-year enhancement as the other two synoptic variables. Not only does IWV show minimal variability between years, but the IWV is larger for both the average and leading snowstorm conditions in Mokelumne during 2015. The opposite is observed in Kaweah. Note that a warmer atmosphere can hold more moisture such that IWV can increase while snowfall decreases. Although WY 2015 was dry and warm, 1986 was wet and warm. Furthermore, across the Sierra Nevada, stronger and statistically significant correlations between $\beta$ and IVT were observed as opposed to correlations between $\beta$ and IWV (not shown), which often were not statistically different from zero since $p>0.05$. Rutz et al. (2014) similarly found precipitation to be more strongly correlated to IVT than to IWV over the mountainous western United States during the winter. Hence, further quantification of synoptic conditions focuses on $u_{700}$ and IVT and is expanded to each watershed below.

\section{2) WET-YEAR AND DRY-YEAR OROGRAPHICALLY DRIVEN CS}

Figure 8 extends the analysis of orographic CS to all wet and dry years across the 14 basins and demonstrates how the snowstorm characteristics discussed a)

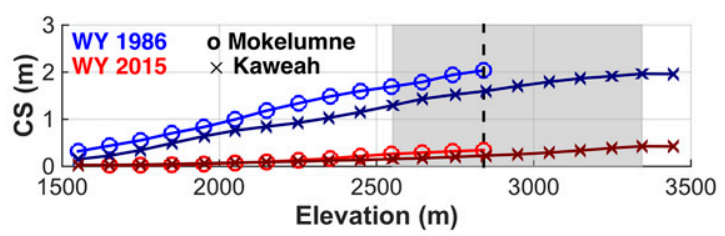

b)

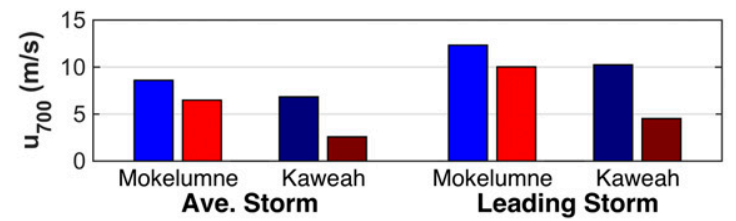

c)

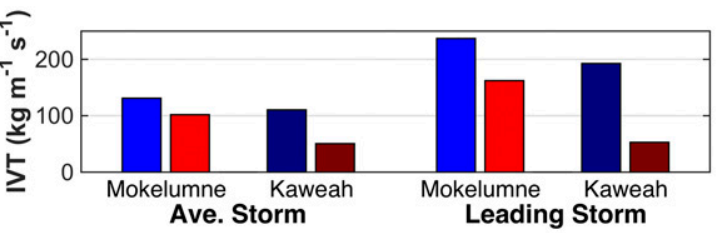

d)

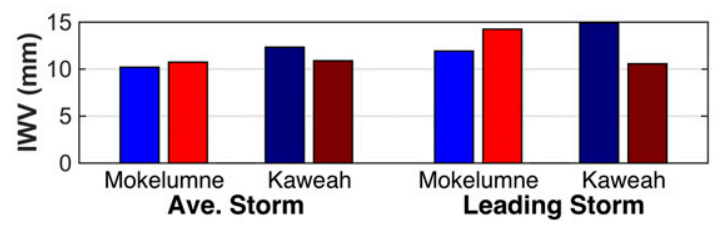

FIG. 7. Seasonal and snowstorm characteristics for Mokelumne and Kaweah during WYs 1986 (blue) and 2015 (red). (a) Seasonal orographic CS curves, where circles and crosses represent Mokelumne and Kaweah, respectively. Elevation zone $\mathrm{EZ}_{2}$ is shaded gray and spans the entire shaded region for Kaweah, but the dashed line demarcates the upper bound of $\mathrm{EZ}_{2}$ for Mokelumne. Average synoptic snowstorm and leading storm (b) $u_{700}$, (c) IVT, and (d) IWV. Lighter shades of blue/red correspond to Mokelumne, while darker shades correspond to Kaweah in all panels.

above manifest themselves in wet-year and dry-year orographic CS. Wet years are more orographically enhanced than dry years, which is evidenced by the steeper slopes exhibited by the wet-year curves in Fig. 8. In agreement with linear theory (Smith 1979), the increase in $\bar{\beta}_{w}$ associated with the average wet-year curve (blue) may be considered a "multiplicative scaling" of the average dry-year curve (red) because the vapor transport, etc., varies interannually (discussed below), leading to interannual variability in the orographic distribution of CS. Although linear theory predicts a multiplicative relationship of orographic distributions among years, nonlinearities impact orographic precipitation distributions (Smith 1979; Smith and Barstad 2004; Hughes et al. 2009; Lundquist et al. 2010). As shown in Fig. 8, the greater orographic enhancement occurring during wet years is evident where $\bar{\beta}_{w} / \bar{\beta}_{d}>1$ (Table 1 ). This is observed across all basins (except Tuolumne) in both $\mathrm{EZ}_{1}$ and $\mathrm{EZ}_{2}$.

As summarized in Table 1, the largest values of $\bar{\beta}_{w}$ and $\bar{\beta}_{d}$ in $\mathrm{EZ}_{1}$ were estimated to be 11.8 (Tuolumne) and $5.5 \mathrm{~cm}$ per $100 \mathrm{~m}$ (Cosumnes), respectively. The SW has 

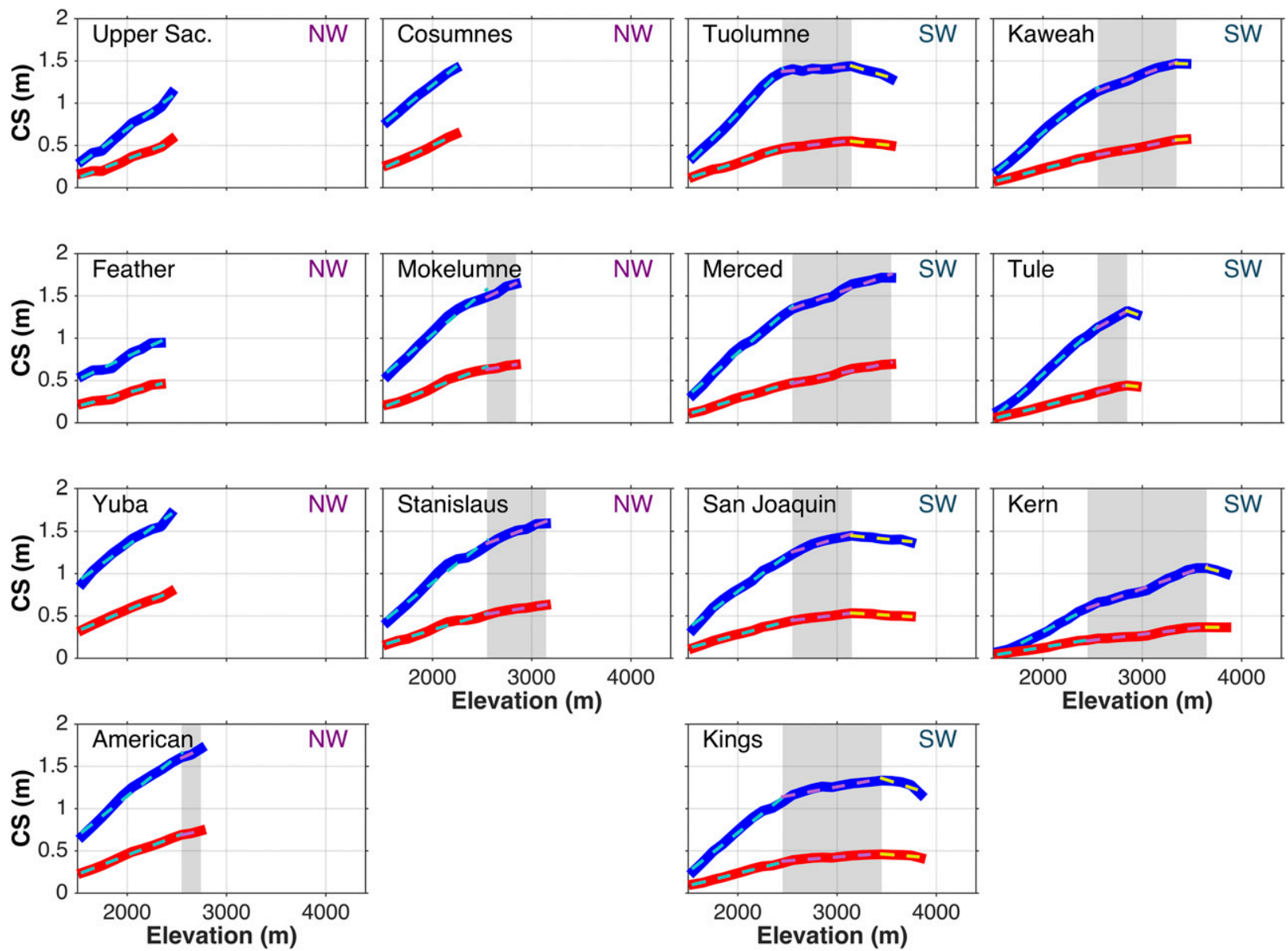

FIG. 8. Elevational distribution of CS where solid lines indicate the wet-year (blue) and dry-year (red) averages. Dashed lines correspond to the lines of best fit for each elevation zone, and $\mathrm{EZ}_{2}$ is shaded gray.

larger gradients than the NW Sierra Nevada in $\mathrm{EZ}_{1}$ during wet years; however, this is reversed in $\mathrm{EZ}_{2}$ and during dry years. The relative rate of enhancement (i.e., $\left.\bar{\beta}_{w} / \bar{\beta}_{d}\right)$ in the SW is $\sim 3.1$ and 2.1 in the first two zones whereas values of 2.0 and 2.4 occur, respectively, in the NW. Thus, the degree of wet-year enhancement varies by region and elevation zone. Overall, the western Sierra Nevada experiences roughly twice as much enhancement during wet years as in dry years in $\mathrm{EZ}_{1}$ and $\mathrm{EZ}_{2}$. The rate of decline in CS is $\sim 10$ times larger during wet years (than dry years) in $\mathrm{EZ}_{3}$ in the SW. However, neglecting the extremely large ratio (Kern) and negative ratio (Kaweah) in Table 1, the average ratio is $\sim 3.1$. For individual basins, the relative rate of enhancement is generally lower in $\mathrm{EZ}_{2}$ than $\mathrm{EZ}_{1}$, indicating that elevations below $\sim 2500 \mathrm{~m}$ tend to be relatively more orographically enhanced.

In Figs. 6a, 6b, and 8, wet years dominate the largest orographic gradients observed in $\mathrm{EZ}_{1}$ and $\mathrm{EZ}_{2}$ across all watersheds, with WY 1986 producing $\sim 67 \%$ of the largest basinwide gradients in these two zones. Overall, wet years yielded $\sim 87 \%$ of the steepest gradients. Dry years make up the largest fraction of years with the most gradual CS-elevation increases for each basin (Fig. 6), with WYs 2001 and 2015 accounting for the largest number of these gradients.

\section{e. Attribution of orographic enhancement}

\section{1) HORIZONTAL MOISTURE TRANSPORT AND WIND PATTERNS}

Large-scale moisture transport and wind predominantly come from the southwest and west during snowstorms across the Sierra Nevada (Fig. 9). The basin-average terrain aspect of the majority of basins corresponds to southwest/west-facing (dashed line in Fig. 9), while Kern and Feather have south-facing basin-average terrain aspects. Therefore, 12 of the 14 basins have average terrain aspects that are more prone to facing into the dominant winds that transport moisture to this range. While the 

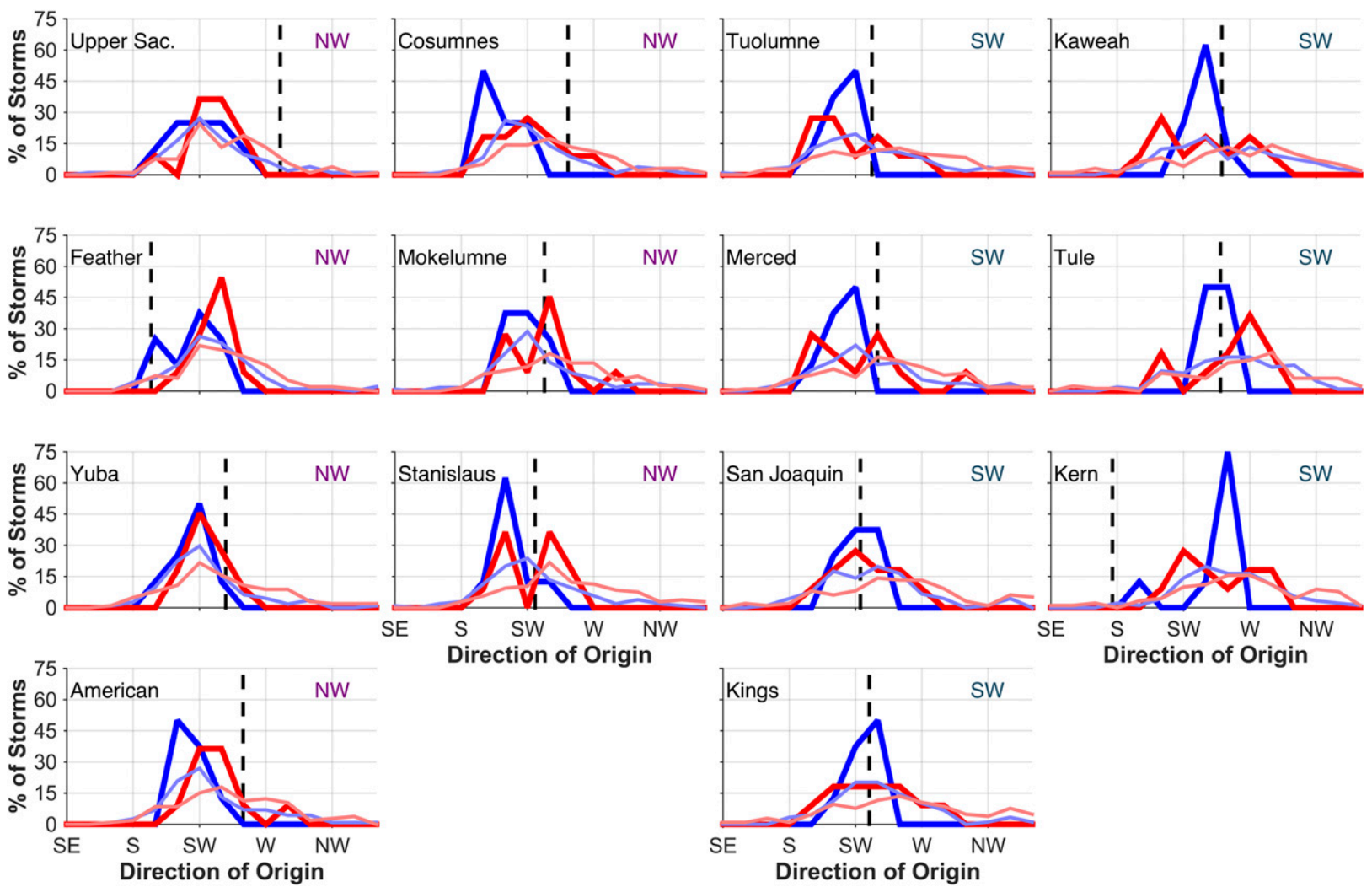

FIG. 9. IVT direction of origin as a percent of the total number of snowstorms over all wet (blue) and dry (red) years for each basin using $15^{\circ}$ bins. Lighter and darker lines represent all snowstorms and leading snowstorms, respectively. Dashed lines demarcate the basinaverage terrain aspect values. Negligible fractions of storms originated outside of those directions shown.

basin-average terrain aspect of the Upper Sacramento is similar to the other basins, its overall configuration is different (Fig. 1a). Lower elevations (in particular) in both Kern and Feather tend to be more sheltered or obstructed by terrain such that localized rain shadows can form. This is manifested by these two basins (located at opposite ends of the mountain range) having the lowest orographic gradients in $\mathrm{EZ}_{1}$ over each averaging period (Table 1), even though Feather receives moisture transported northward via the SBJ. Furthermore, Fig. 6a shows that at these lowest elevations, both basins have the smallest maximum gradients out of all basins at $8.8-9.0 \mathrm{~cm}$ per $100 \mathrm{~m}$. While alignment between the prevailing wind direction and the terrain aspect would be expected to provide the greatest orographic enhancement (Fig. 2e), there tends to be a relatively narrow range of prevailing IVT directions during the snowstorms analyzed herein (Fig. 9). Thus, "perfect" alignment is not necessarily achieved across basins; however, the basin-average terrain aspects generally face into the prevailing wind field, which promotes orographic enhancement.

Figure 9 presents the distribution of prevailing transport directions during all snowstorms in a basin for wet and dry years in lighter shades of blue and red, respectively. It indicates that the percent of storms from the SW is often greater during wet years; however, directions do not greatly vary between years. While the IVT directions may be similar, the IVT magnitudes (and inherently wind speeds) can greatly differ between storms and years, leading to differences in orographic enhancement as shown in Figs. 4 and 6-8 and further discussed below. Figure 9 also demonstrates that the predominant direction that leading snowstorms (darker/ thicker curves) originate from is the same direction as when all snowstorms (lighter/thinner curves) are considered; however, a larger percentage of the leading snowstorms tend to originate from these prevailing directions than when all storms are considered. Southwesterlies dominate the snowstorm record, which is consistent with previous literature (e.g., Lundquist et al. 2015). Overall, transport from the SW yields the largest snowstorms of the season that have high water vapor and favorable alignment with the terrain aspect, and thereby promote orographic enhancement.

Maps of average IVT conditions during snowstorms over the range are presented in Fig. 10. They depict the 

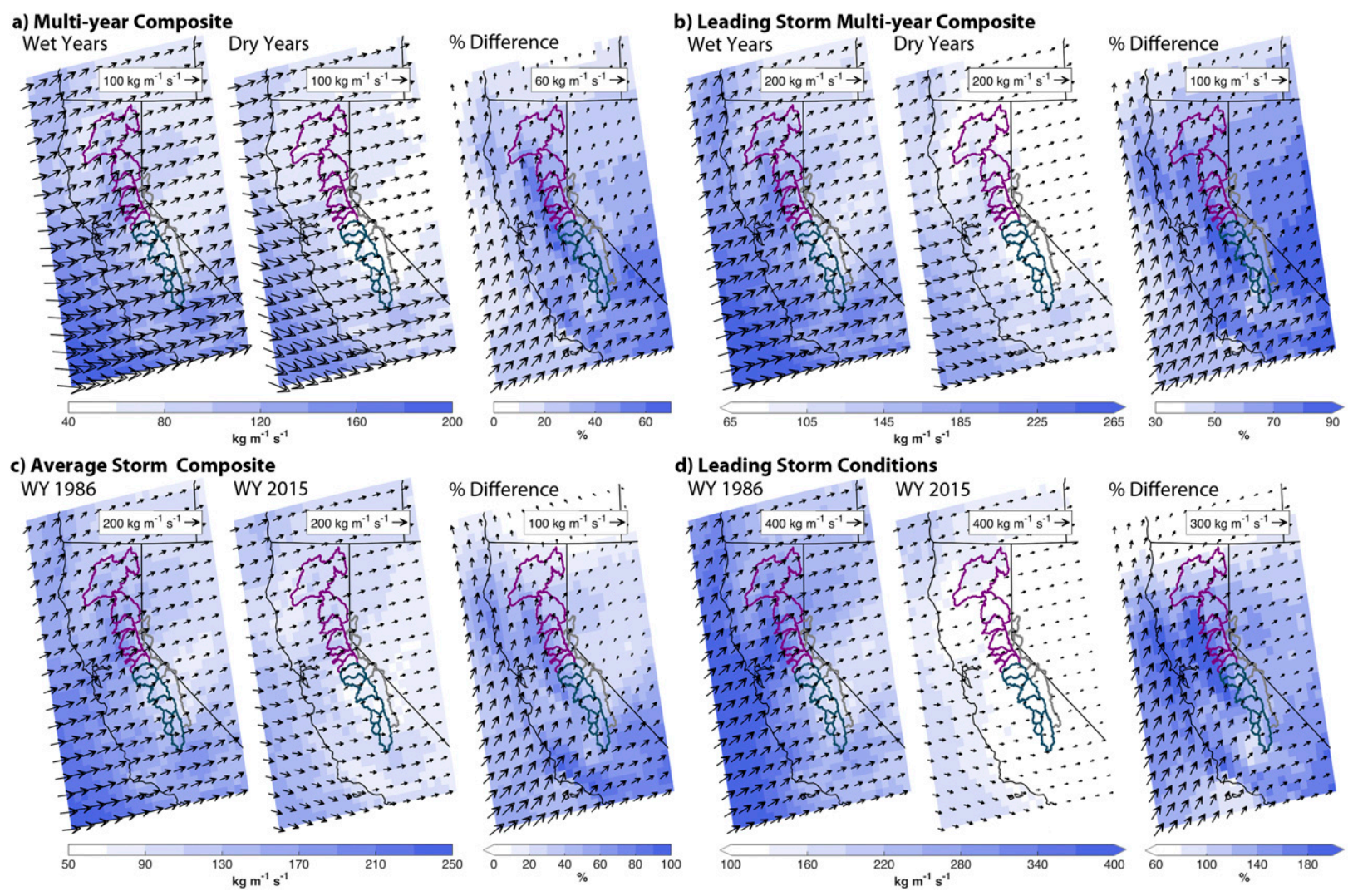

FIG. 10. The first two maps in each panel show average IVT $\left(\mathrm{kg} \mathrm{m}^{-1} \mathrm{~s}^{-1}\right)$ across all storms in (a) wet and dry years and (c) WYs 1986 and 2015 and leading storms in (b) wet and dry years and (d) WYs 1986 and 2015, respectively. In the last map in each panel, arrows denote the IVT vector difference (first minus second vector fields) and shading indicates the percent difference given by $\%$ difference $=\left(\left|\mathrm{IVT}_{1}\right|-\left|\mathrm{IVT}_{2}\right|\right) /\left|\mathrm{IVT}_{2}\right| \times 100 \%$, where $\left|\mathrm{IVT}_{1}\right|$ and $\left|\mathrm{IVT}_{2}\right|$ are the magnitudes of the first and second IVT maps in each set, respectively.

magnitude and direction of IVT ranging from multiyear composites of average storm conditions in Fig. 10a to single events in Fig. 10d. Across each set of percent difference maps (rightmost maps in Figs. 10a-d), wet years and their leading snowstorms have higher IVT than dry years, with large relative differences observed along the western basins. Although the directions of the vectors are markedly similar between the leading storm composites in Fig. 10b, the percent differences relative to the dry years are large $(32.7 \%-104.4 \%)$. The greatest relative differences between wet and dry years are evident at the leading storm scale with a maximum difference of $219.4 \%$ (Fig. 10d). Even when the IVT vectors are similar in the northernmost basins in WYs 1986 and 2015 (Fig. 10c), the storm conditions still indicate higher overall IVT during the wet year, which had more storms (and longer integrated storm duration) than 2015 (HM17). Therefore, while these maps (near/over the western basins) are consistent with the dominant transport directions identified in Fig. 9, they provide additional information about the variability of IVT magnitudes and storm directions across the range and within California.

\section{2) ATMOSPHERIC SYNOPTIC FEATURES AND OROGRAPHIC CS GRADIENTS}

Of the average synoptic snowstorm conditions considered above (i.e., $u_{700}$, IVT, and IWV), $u_{700}$ wind speeds and IVT magnitudes are further investigated to better understand the drivers of orographic enhancement and how these synoptic features impact the interannual variability of orographic gradients across the Sierra Nevada. The above discussion and Figs. 2, 7, and 10 suggest strong correlations between orographic gradients and both IVT and $u_{700}$. For the abovementioned reasons, the primary focus is on both $\mathrm{EZ}_{1}$ and $E Z_{2}$, which make up the largest fraction of the area among basins.

Table 2 shows the correlation coefficients between seasonal orographic CS gradients in each elevation zone and $u_{700}$ and IVT for the 14 basins. The stronger correlations overall (boldface) generally occur between the 
TABLE 2. Correlation coefficients between the seasonal orographic gradients $\beta$ in each elevation zone and average snowstorm $u_{700}$ and IVT in each basin. All correlations are statistically significant, except where indicated. Strongest statistically significant correlations for each basin and $\mathrm{EZ}$ are in bold.

\begin{tabular}{|c|c|c|c|c|c|c|}
\hline \multirow[b]{2}{*}{ Basin } & \multicolumn{3}{|c|}{$\beta$ and $u_{700}$} & \multicolumn{3}{|c|}{$\beta$ and IVT } \\
\hline & $\mathrm{EZ}_{1}$ & $\mathrm{EZ}_{2}$ & $\mathrm{EZ}_{3}$ & $\mathrm{EZ}_{1}$ & $\mathrm{EZ}_{2}$ & $\mathrm{EZ}_{3}$ \\
\hline Upper Sacramento & 0.49 & - & - & 0.52 & - & - \\
\hline Feather & 0.52 & - & - & 0.43 & - & - \\
\hline Yuba & 0.64 & - & - & 0.61 & - & - \\
\hline American & 0.56 & 0.68 & - & 0.52 & 0.66 & - \\
\hline Cosumnes & $0.34^{\mathrm{a}}$ & - & - & $0.28^{\mathrm{a}}$ & - & - \\
\hline Mokelumne & 0.64 & 0.77 & - & 0.65 & 0.80 & - \\
\hline Stanislaus & 0.55 & 0.60 & - & 0.67 & 0.72 & - \\
\hline Tuolumne & 0.40 & 0.50 & -0.52 & 0.42 & 0.68 & -0.49 \\
\hline Merced & 0.48 & 0.67 & - & 0.43 & 0.84 & - \\
\hline San Joaquin & 0.45 & 0.40 & $0.01^{\mathrm{a}}$ & 0.46 & 0.62 & $-0.04^{\mathrm{a}}$ \\
\hline Kings & 0.44 & 0.36 & -0.58 & 0.43 & 0.54 & -0.51 \\
\hline Kaweah & 0.66 & 0.45 & $0.04^{\mathrm{a}}$ & 0.55 & 0.54 & $-0.07^{\mathrm{a}}$ \\
\hline Tule & 0.53 & $0.59^{\mathrm{b}}$ & -0.39 & 0.37 & $0.59^{\mathrm{b}}$ & $-0.30^{\mathrm{a}}$ \\
\hline Kern & $0.25^{\mathrm{a}}$ & 0.57 & $-0.54^{b}$ & $0.18^{\mathrm{a}}$ & 0.65 & $-0.54^{b}$ \\
\hline
\end{tabular}

${ }^{a}$ Not statistically significant $(p>0.05)$.

${ }^{\mathrm{b}}$ Strongest statistically significant correlations appear in both $u_{700}$ and IVT groups (i.e., the absolute value of the difference in correlation coefficients between the $u_{700}$ group and the IVT group is negligible).

orographic gradients and IVT, with higher correlations most evident in $\mathrm{EZ}_{2}$. On average, the $\beta$ and IVT correlations are larger in $\mathrm{EZ}_{2}$ than those associated with $u_{700}$ by $\sim 0.1$. Roughly half of the largest correlation coefficients in $\mathrm{EZ}_{1}$ are split between $\beta$ and $u_{700}$ and between $\beta$ and IVT, and the differences between the correlations have a magnitude of less than 0.1 averaged across basins. The correlations in Table 2 are statistically significant, with only two basins (Cosumnes and Kern) having weak (statistically insignificant) correlations in $\mathrm{EZ}_{1}$. The weakest correlations found in $\mathrm{EZ}_{1}$ were in Kern, which likely resulted from its north-south orientation that largely shelters the lowest elevations from the prevailing wind. In addition, the complex terrain upwind of Kern (e.g., Kaweah and Tule basins to the west of Kern) may also impact the correlations observed for Kern. Both Cosumnes and Kern have the weakest correlations between CS and slope (not shown), which may contribute to the correlations between the synoptic features and CS gradients not being statistically different from zero in Table 2.

The combination of stronger wind speeds and greater precipitable water leads to increased IVT, which enhances orographic CS gradients (Table 2). To illustrate this, Fig. 11 shows the average wet-year (blue line), dryyear (red line), and 31-yr (dashed line) snowstorm horizontal vapor transport profiles above the surface for each basin. The interannual variability in the wet-year and dry- year profiles is demarcated by the shaded regions in their respective colors. These profiles represent average atmospheric profiles during a broadly defined set of snowstorms. While the snowstorms considered herein include specific atmospheric structures such as precipitationintensive AR events, the analysis more generally considers both small/weak and large/intense snowfall events.

As shown in Fig. 11, higher vapor transport occurs near or above the highest elevations in the Sierra Nevada. Moving upslope within a watershed, vapor transport "builds up" with elevation, leading to greater potential enhancement. Thus, both wind and moisture at upwind locations can have a cumulative (integrated) effect with elevation (increased winds with height and conservation of moisture not lost to the atmosphere, etc.) and promote orographically enhanced CS at higher elevations downwind. Note, however, that moist air beginning at a higher elevation may have less uplift potential because of a smaller vertical rise over a mountain. Stronger overall correlations between $\beta$ and IVT are therefore observed in $\mathrm{EZ}_{2}$ as opposed to $\mathrm{EZ}_{1}$. In addition, it is hypothesized that higher correlations are observed in $\mathrm{EZ}_{2}$ because of the presence of the SBJ that influences the atmospheric controlling layer during the season (Neiman et al. 2013). The SW basins that have larger correlations in $\mathrm{EZ}_{1}$ between $\beta$ and $u_{700}$ than between $\beta$ and IVT (Table 2) tend to have lower vapor transport values than in other basins at the lowest elevations (Fig. 11). Also, the slope of each basin (Fig. 5b) tends to increase with elevation, particularly in $\mathrm{EZ}_{2}$, and as described by linear theory, steeper terrain/slopes promote orographic enhancement.

In addition, there is often significant overlap between the wet-year and dry-year interquartile ranges for these basins (e.g., Kings, Kaweah, and Tule). Along with Feather and Yuba, they also have lower interannual variability in the vapor transport at these altitudes. Basins in the central Sierra Nevada exhibit the largest interannual variability and the strongest correlations overall (Table 2). The profiles in Fig. 11 explain the relationships exemplified in Table 2. Both moisture and sufficient wind speed (i.e., transport mechanisms) should exist at a given location or downslope for orographic precipitation to occur.

Furthermore, humidity profiles decrease with altitude (Fig. 12, dotted line). While the vapor transport (Fig. 11) and wind speed profiles (Fig. 12, blue and red) tend to exhibit a noticeable difference (or separation) between the profiles in wet and dry years, this is not observed in the humidity profiles (Fig. 12, cyan and magenta), which have low interannual variability. In agreement with linear theory, although lower elevations tend to have higher humidity, abundant moisture does not necessarily indicate that orographic enhancement will occur 

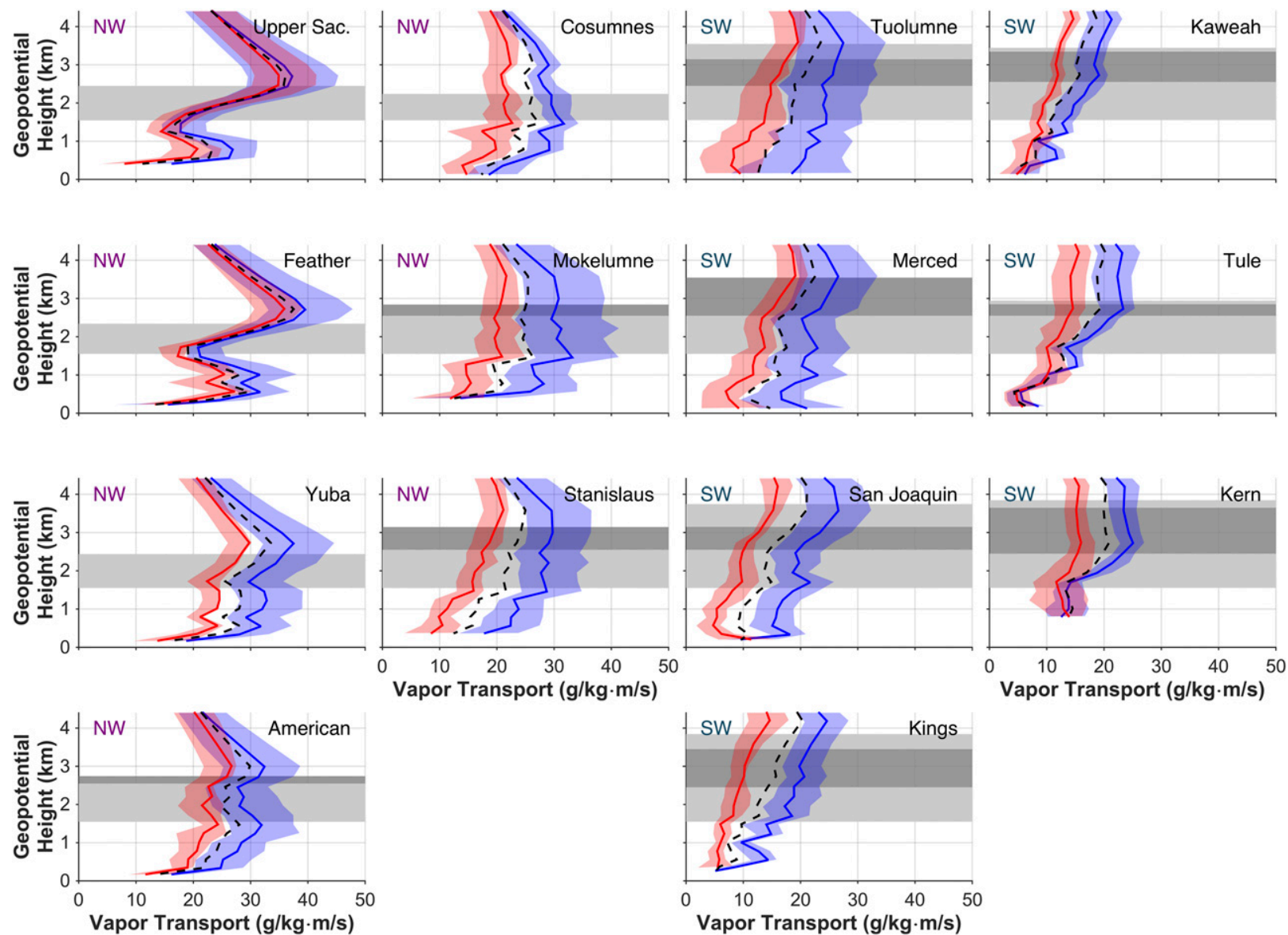

FIG. 11. Wet-year (blue line), dry-year (red line), and 31-yr (dashed line) average magnitude of the horizontal vapor transport profiles. Interquartile ranges for wet and dry years are shaded in their respective colors. Elevation zones are shaded in light gray $\left(\mathrm{EZ}_{1}\right.$ and $\left.\mathrm{EZ}_{3}\right)$ and dark gray $\left(\mathrm{EZ}_{2}\right)$, where appropriate. The NW and SW labeling demarcates the region that the basin resides in Fig. 1a, not the direction of the vapor transport.

without sufficient winds. This explains why IVT and $u_{700}$ display a stronger relationship with orographic gradients than IWV. While $700 \mathrm{hPa}$ corresponds to a geopotential height of roughly $3000 \mathrm{~m}$, stronger $u_{700}$ winds are generally indicative of stronger zonal winds at all altitudes since wind speeds typically increase with altitude (Fig. 12), and the westerlies prevail across California. Stronger winds favoring orographic enhancement were often observed during snowstorms in wet years (Fig. 12), which supports the presence of positive correlations between $u_{700}$ and $\beta$ even at lower elevations.

These findings explain the wet-year enhancement exemplified in Figs. 6-8 and the correlations presented in Table 2. Thus, while wind speed and moisture are both important components in the generation of orographically driven CS, wind speeds are more important in the Sierra Nevada. Nonetheless, IVT exerts a more complex control on orographic enhancement because it combines moisture availability (Fig. 2a) with wind fields (Fig. 2b). At elevations with a higher cumulative vapor transport effect (e.g., $\mathrm{EZ}_{2}$ ), $\beta$ tends to exhibit stronger correlations with IVT than $u_{700}$. When transport is lower (Fig. 11), the $u_{700}$ correlations are larger in the case of the lowest elevations (Table 2). Other ranges similar to the Sierra Nevada are expected to respond likewise to higher IVT and $u_{700}$, which promote greater orographic enhancement and lead to wet years displaying greater enhancement than dry years.

Stronger correlations in the Sierra Nevada are generally found between the orographic gradients and $u_{700}$ at higher elevations (i.e., $\mathrm{EZ}_{2}$ versus $\mathrm{EZ}_{1}$ ). Since Luce et al. (2013) similarly found stronger correlations between cumulative precipitation and $u_{700}$ at higher elevations in the Pacific Northwest, insight into orographic CS derived herein is likely applicable to many other mountain ranges. As demonstrated here, stronger winds promote orographic enhancement at higher elevations, where it can be more pronounced. At the lowest elevations, the prevailing wind has the greatest probability of being obstructed by the terrain or features such as the 

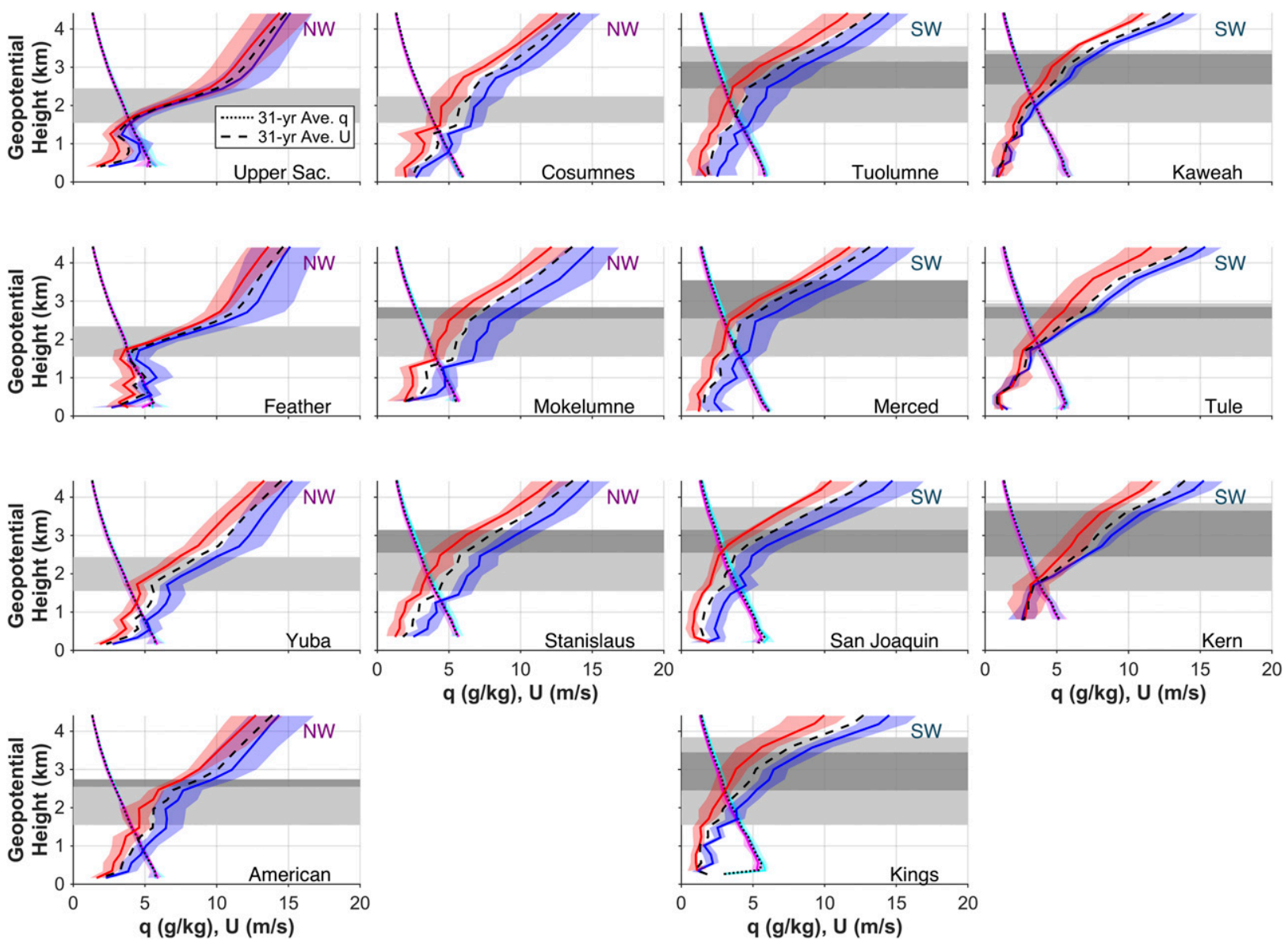

FIG. 12. As in Fig. 11, but the profiles for wet years (dry years) are shown in cyan (magenta) for specific humidity $q$ and blue (red) for wind speed $U$, respectively.

SBJ, which would result in localized wind patterns at these elevations that differ more from the large-scale wind (taken as $u_{700}$ ). However, correlations indicate that larger $u_{700}$ values are often indicative of stronger winds even at lower altitudes (not shown).

\section{Conclusions}

This paper provides a more comprehensive analysis (spanning 31 years and 14 windward basins) of the interannual variability of orographically enhanced CS and gradients, wet-year versus dry-year enhancement, and the key drivers of enhancement than previously available for high-elevation mountain ranges. Variability in orographic gradients indicates changes in the elevational distribution of CS, which has water resources and climate change implications (Pavelsky et al. 2012) and is driven by variability in atmospheric conditions.

An important implication of stronger winds and transport observed during wet years is that while windy conditions promote enhancement, windier conditions often lead to increased undercatch by gauges/sensors (Rasmussen et al. 2012). Thus, such conditions would likely result in misrepresentations of orographic snowfall distributions that may be exacerbated by undersampling high elevations with in situ measurements. Furthermore, a warmer climate will allow the atmosphere to hold more water vapor, and IVT is projected to increase in the future in the midlatitudes along the west coast of North America (Lavers et al. 2015). Lavers et al. (2015) found that a potential increase in IVT of $\sim 20 \%-40 \%$ may occur in the wintertime, which thereby could increase orographic gradients. The findings herein indicate that future modulation of IVT fields would have significant implications across the Sierra Nevada, altering the distribution of CS and orographic enhancement. These findings are likely extensible to other similar mountain ranges.

Insights presented herein could be used to evaluate the ability of climate models to accurately diagnose high-elevation CS gradients and distributions in montane regions. Since climate models often struggle with 
the representation of orographic snowfall processes, results could inform the development of parameterizations that leverage the resolved synoptic atmospheric features in climate models (i.e., IVT and $u_{700}$ ) and their relationships with orographic CS gradients to better predict future montane CS distributions. Such parameterizations may also be utilized in downscaling applications from sparse station data and/or coarse gridded precipitation information to improve climate studies and applications that commonly use multiplicative relationships since they may not fully represent annual precipitation distributions (Lundquist et al. 2010; Kirchner et al. 2014).

Acknowledgments. This work was partially supported by the NASA Earth and Space Science Graduate Fellowship NNX14AK75H, NASA NEWS Grant NNX15AD16G, and NSF Grant EAR-1246473. This research is part of the NSF Blue Waters sustained petascale supercomputing project. The snow reanalysis is available from http://aqua.seas.ucla.edu/data. NARR was obtained from the NOAA National Climatic Data Center.

\section{REFERENCES}

Aguado, E., 1990: Elevational and latitudinal patterns of snow accumulation departures from normal in the Sierra Nevada. Theor. Appl. Climatol., 42, 177-185, https://doi.org/10.1007/ BF00866873.

Alpert, P., 1986: Mesoscale indexing of the distribution of orographic precipitation over high Mountains. J. Climate Appl. Meteor., 25, 532-545, https://doi.org/10.1175/1520-0450(1986)025<0532: MIOTDO $>2.0 . \mathrm{CO} ; 2$.

Barnett, T. P., J. C. Adam, and D. P. Lettenmaier, 2005: Potential impacts of a warming climate on water availability in snowdominated regions. Nature, 438, 303-309, https://doi.org/ 10.1038/nature04141.

Barros, A. P., and D. P. Lettenmaier, 1994: Dynamic modeling of orographically induced precipitation. Rev. Geophys., 32, 265-284, https://doi.org/10.1029/94RG00625.

Cayan, D. R., E. P. Mauere, M. D. Dettinger, M. Tyree, and K. Hayhoe, 2008: Climate change scenarios for the California region. Climatic Change, 87 (Suppl.), 21-42, https://doi.org/ 10.1007/s10584-007-9377-6.

Colle, B. A., 2004: Sensitivity of orographic precipitation to changing ambient conditions and terrain geometries: An idealized modeling perspective. J. Atmos. Sci., 61, 588-606, https://doi.org/ 10.1175/1520-0469(2004)061<0588:SOOPTC $>2.0 . C O ; 2$.

Dettinger, M. D., K. Redmond, and D. Cayan, 2004: Winter orographic precipitation ratios in the Sierra Nevada-Large-scale atmospheric circulations and hydrologic consequences. J. Hydrometeor., 5, 1102-1116, https://doi.org/10.1175/JHM-390.1.

Downing, J., 2015: Forest thinning may increase water yield from the Sierra Nevada. Calif. Agric., 69, 10-11, https://doi.org/ 10.3733/ca.v069n01p10.

Galewsky, J., and A. Sobel, 2005: Moist dynamics and orographic precipitation in northern and central California during the
New Year's Flood 1997. Mon. Wea. Rev., 133, 1594-1612, https://doi.org/10.1175/MWR2943.1.

Grubišić, V., R. K. Vellore, and A. W. Huggins, 2005: Quantitative precipitation forecasting of wintertime storms in the Sierra Nevada: Sensitivity to the microphysical parameterizations and horizontal resolution. Mon. Wea. Rev., 133, 2834-2859, https://doi.org/10.1175/MWR3004.1.

Grünewald, T., Y. Buhler, and M. Lehning, 2014: Elevation dependency of mountain snow depth. Cryosphere, 8, 2381-2394, https://doi.org/10.5194/tc-8-2381-2014.

Guan, B., and D. E. Waliser, 2015: Detection of atmospheric rivers: Evaluation and application of an algorithm for global studies. J. Geophys. Res. Atmos., 120, 12 514-12 535, https:// doi.org/10.2002/2015JD024257.

, N. P. Molotch, D. E. Waliser, E. J. Fetzer, and P. J. Neiman, 2010: Extreme snowfall events linked to atmospheric rivers and surface air temperature via satellite measurements. Geophys. Res. Lett., 37, L20401, https://doi.org/10.1029/2010GL044696.

Houze, R. A., Jr., 2012: Orographic effects on precipitating clouds. Rev. Geophys., 50, RG1001, https://doi.org/10.1029/ 2011RG000365.

Hughes, M., A. Hall, and R. G. Fovell, 2009: Blocking in areas of complex topography, and its influence on rainfall distribution. J. Atmos. Sci., 66, 508-518, https://doi.org/10.1175/ 2008JAS2689.1.

— , P. J. Neiman, E. Sukovich, and M. Ralph, 2012: Representation of the Sierra barrier jet in 11 years of a high-resolution dynamical reanalysis downscaling compared with long-term wind profiler observations. J. Geophys. Res., 117, D18116, https://doi.org/10.1029/2012JD017869.

Huning, L. S., and S. A. Margulis, 2017: Climatology of seasonal snowfall accumulation across the Sierra Nevada (USA): Accumulation rates, distributions, and variability. Water Resour Res., 53, 6033-6049, https://doi.org/10.1002/2017WR020915.

,-- , B. Guan, D. E. Waliser, and P. J. Neiman, 2017: Implications of detection methods on characterizing atmospheric river contribution to seasonal snowfall across Sierra Nevada, USA. Geophys. Res. Lett., 44, $10445-10453$, https://doi.org/ 10.1002/2017GL075201.

Kapnick, S., and A. Hall, 2010: Observed climate-snowpack relationships in California and their implications for the future. J. Climate, 23, 3446-3456, https://doi.org/10.1175/2010JCLI2903.1.

Kirchner, P. B., R. C. Bales, N. P. Molotch, J. Flanagan, and Q. Guo, 2014: LiDAR measurement of seasonal snow accumulation along an elevation gradient in the southern Sierra Nevada, California. Hydrol. Earth Syst. Sci., 18, 4261-4275, https://doi.org/10.5194/hess-18-4261-2014.

Lavers, D. A., G. Villarini, R. A. Allan, E. F. Wood, and A. J. Wade, 2012: The detection of atmospheric rivers in atmospheric reanalyses and their links to British winter floods and the large-scale climatic circulation. J. Geophys. Res., 117, D20106, https://doi.org/10.1029/2012JD018027.

—, F. M. Ralph, D. E. Waliser, A. Gershunov, and M. D. Dettinger, 2015: Climate change intensification of horizontal water vapor transport in CMIP5. Geophys. Res. Lett., 42, 5617-5625, https://doi.org/10.1002/2015GL064672.

Lehning, M., 2013: Snow-atmosphere interactions and hydrological consequences. Adv. Water Resour., 55, 1-3, https://doi.org/ 10.1016/j.advwatres.2013.02.001.

Leung, L. R., and S. J. Ghan, 1998: Parameterizing subgrid orographic precipitation and surface cover in climate models. Mon. Wea. Rev., 126, 3271-3291, https://doi.org/10.1175/ 1520-0493(1998)126<3271:PSOPAS > 2.0.CO;2. 
Luce, C. H., J. T. Abatzoglou, and Z. A. Holden, 2013: The missing mountain water: Slower westerlies decrease orographic enhancement in the Pacific Northwest USA. Science, 342, 1360-1364, https://doi.org/10.1126/science.1242335.

Lundquist, J. D., P. J. Neiman, B. Martner, A. B. White, D. J. Gottas, and F. M. Ralph, 2008: Rain versus snow in the Sierra Nevada, California: Comparing Doppler profiling radar observations of melting level. J. Hydrometeor., 9, 194-211, https://doi.org/10.1175/2007JHM853.1.

— , J. R. Minder, P. J. Neiman, and E. Sukovich, 2010: Relationships between barrier jet heights, orographic precipitation gradients, and streamflow in the northern Sierra Nevada. J. Hydrometeor., 11, 1141-1156, https://doi.org/ 10.1175/2010JHM1264.1.

- M. Hughes, B. Henn, E. Gutmann, B. Livenh, J. Dozier, and P. Neiman, 2015: High-elevation precipitation patterns: Using snow measurements to assess daily gridded datasets across the Sierra Nevada, California. J. Hydrometeor., 16, 1773-1792, https://doi.org/10.1175/JHM-D-15-0019.1.

Margulis, S., M. Girotto, G. Cortés, and M. Durand, 2015: A particle batch smoother approach to snow water equivalent estimation. J. Hydrometeor., 16, 1752-1772, https://doi.org/ 10.1175/JHM-D-14-0177.1.

_ , G. Cortés, M. Girotto, and M. Durand, 2016: A Landsat-era Sierra Nevada snow reanalysis (1985-2015). J. Hydrometeor., 17, 1203-1221, https://doi.org/10.1175/JHM-D-15-0177.1.

Mesinger, F., and Coauthors, 2006: North American Regional Reanalysis. Bull. Amer. Meteor. Soc., 87, 343-360, https:// doi.org/10.1175/BAMS-87-3-343.

Mote, P. W., A. F. Hamlet, M. P. Clark, and D. Lettenmaier, 2005: Declining mountain snowpack in western North American. Bull. Amer. Meteor. Soc., 86, 39-49, https://doi.org/10.1175/ BAMS-86-1-39.

Neiman, P. J., M. Hughes, B. J. Moore, F. M. Ralph, and E. S. Sukovich, 2013: Sierra barrier jets, atmospheric rivers, and precipitation characteristics in Northern California: A composite perspective based on a network of wind profilers. Mon. Wea. Rev., 141, 4211-4233, https://doi.org/10.1175/MWR-D13-00112.1.

O'Hara, B. F., M. L. Kaplan, and S. J. Underwood, 2009: Synoptic climatology analyses of extreme snowfalls in the Sierra Nevada. Wea. Forecasting, 24, 1610-1624, https://doi.org/10.1175/ 2009WAF2222249.1.
Pandey, G. R., D. R. Cayan, and K. P. Georgakakos, 1999: Precipitation structure in the Sierra Nevada of California during winter. J. Geophys. Res., 104, 12 019-12 030, https://doi.org/ 10.1029/1999JD900103.

Pavelsky, T. P., S. Sobolowski, S. B. Kapnick, and J. B. Barnes, 2012: Changes in orographic precipitation patterns caused by a shift from snow to rain. Geophys. Res. Lett., 39, L18706, https://doi.org/10.1029/2012GL052741.

Ralph, F. M., P. J. Neiman, G. A. Wick, S. I. Gutman, M. D. Dettinger, D. R. Cayan, and A. B. White, 2006: Flooding on California's Russian River: Role of atmospheric rivers. Geophys. Res. Lett., 33, L13801, https://doi.org/10.1029/2006GL026689.

Rasmussen, R., and Coauthors, 2012: How well are we measuring snow? The NOAA/FAA/NCAR winter precipitation test bed. Bull. Amer. Meteor. Soc., 93, 811-829, https://doi.org/10.1175/ BAMS-D-11-00052.1.

Roe, G. H., 2005: Orographic precipitation. Annu. Rev. Earth Planet. Sci., 33, 645-671, https://doi.org/10.1146/annurev. earth.33.092203.122541.

Rosenthal, W., and J. Dozier, 1996: Automated mapping of montane snow cover at subpixel resolution from the Landsat Thematic Mapper. Water Resour. Res., 32, 115-130, https:// doi.org/10.1029/95WR02718.

Rutz, J. J., W. J. Steenburgh, and F. M. Ralph, 2014: Climatological characteristics of atmospheric rivers and their inland penetration over the western United States. Mon. Wea. Rev., 142, 905-921, https://doi.org/10.1175/MWR-D-13-00168.1.

Serreze, M. C., M. P. Clark, and A. Frei, 2001: Characteristics of large snowfall events in the montane western United States as examined using snowpack telemetry (SNOTEL) data. Water Resour. Res., 37, 675-688, https://doi.org/10.1029/ 2000WR900307.

Smith, R. B., 1979: The influence of mountains on the atmosphere. Advances in Geophysics, Vol. 21, Academic Press, 87-230, https://doi.org/10.1016/S0065-2687(08)60262-9.

— , and I. Barstad, 2004: A linear theory of orographic precipitation. J. Atmos. Sci., 61, 1377-1391, https://doi.org/ 10.1175/1520-0469(2004)061<1377:ALTOOP>2.0.CO;2.

Xia, Y., and Coauthors, 2012: Continental-scale water and energy flux analysis and validation for the North American Land Data Assimilation System project phase 2 (NLDAS-2): 1. Intercomparison and application of model products. J. Geophys. Res., 117, D03109, https://doi.org/10.1029/2011JD016048. 